Research Article

\title{
Stability Assessment of the Excavated Rock Slope at the Dagangshan Hydropower Station in China Based on Microseismic Monitoring
}

\author{
K. Ma ${ }^{1},{ }^{1}$ N. W. Xu ${ }^{D}{ }^{2}$ and Z. Z. Liang ${ }^{1}$ \\ ${ }^{1}$ State Key Laboratory of Coastal and Offshore Engineering, Dalian University of Technology, Dalian, Liaoning 116024, China \\ ${ }^{2}$ State Key Laboratory of Hydraulics and Mountain River Engineering, College of Water Resource and Hydropower, \\ Sichuan University, Chengdu, Sichuan 610065, China
}

Correspondence should be addressed to N. W. Xu; xunuwen@scu.edu.cn

Received 30 January 2018; Revised 12 June 2018; Accepted 13 June 2018; Published 9 July 2018

Academic Editor: Victor Yepes

Copyright (c) 2018 K. Ma et al. This is an open access article distributed under the Creative Commons Attribution License, which permits unrestricted use, distribution, and reproduction in any medium, provided the original work is properly cited.

\begin{abstract}
A high-resolution microseismic (MS) monitoring system was implemented at the right bank slope of the Dagangshan hydropower station in May 2010 to analyse the slope stability subjected to continuous excavation. The MS monitoring system could real-time capture a large number of seismic events occurring inside the rock slope. The identification and delineation of rock mass damage subject to excavation and consolidation grouting can be conducted based on the analysis of tempospatial distribution of MS events. However, how to qualitatively evaluate the stability of the rock slope by utilizing these MS data remains challenging. A damage model based on MS data was proposed to analyse the rock mass damage, and a 3D finite element method model of the rock slope was also established. The deteriorated mechanical parameters of rock mass were determined according to the model elements considering the effect of MS damage. With this method, we can explore the effect of MS activities, which are caused by rock mass damage subjected to excavation and strength degradation to the dynamic instability of the slope. When the MS damage effect was taken into account, the safety factor of the rock slope was reduced by 0.18 compared to the original rock slope model without considering the effect. The simulated results show that MS activities, which are subjected to excavation unloading, have only a limited effect on the stability of the right bank slope. The proposed method is proven to be a better approach for the dynamical assessment of rock slope stability and will provide valuable references for other similar rock slopes.
\end{abstract}

\section{Introduction}

The stability of rock slopes subject to excavation is a major challenge in geotechnical engineering during both the design and construction stages. Many achievements have been made to evaluate the excavation influence of rock slope [1-3]. For instance, Jin proposed that steep terrain had a significant influence on the dynamic behaviour of the slopes under blasting [4]. Guo et al. investigated the relationship between slope type and slope effect value [5]. Wayne discussed the mechanical processes in the rock mass around a kimberlite volcanic excavation that occurred as the rock responded to the formation of the excavation [6]. Lu et al. introduced a modified tensile-compressive damage model to the simulation of the excavation damaged zones of the Xiluodu high rock slope [7]. This model reproduced the excavation damaged zones for high rock slope excavation with the dynamic finite element method. Yang et al. analysed the dynamic behaviour of a high road cutting rock slope under blasting excavation by FLAC $^{3 \mathrm{D}}[8]$. Sato et al. described the results of an in situ excavation disturbance experiment using mechanical excavation with a boom header at the Tono mine and compared the findings with the results obtained using blasting excavation [9]. Kentli and Topal conducted field and laboratory researches to determine the engineering geological properties of rocks exposed along motorways and to assess the excavation behaviour and stability of the cut slopes [10].

Unlike the conventional monitoring methods, which focus only on the information regarding surface movements, 
the microseismic (MS) monitoring data would be sufficient for us to understand the microscale changes occurring inside the rock mass $[11,12]$. Application of the MS technique provides in-depth knowledge of the mechanism associated with rock slope failure through the results of excavated rock mass. The MS monitoring technique is a useful tool for detecting unstable areas of rock slopes and assessing the corresponding hazards. Considerable researches have been conducted on the application of MS/acoustic emissions (AEs) to predict rock slope failures. For example, Ma et al. proposed the stability analysis and reinforcement effect of the slope based on MS energy density and the magnitudefrequency relation [13]. Kolesnikov et al. proposed seismoAE for monitoring slope stability in the north by filtering and polarization analysis [14]. Senfaute et al. examined the MS signals recorded $15 \mathrm{~h}$ prior to a rock fall in Mesnil-Val, France, which offered the possibility of using the MS monitoring system to monitor high-risk sections of coastline and understand the mechanism of cliff failure [15]. Amitrano et al. identified a power law acceleration of seismicity rate and energy before a cliff collapse [16]. Eberhardt et al. presented preliminary MS monitoring results recorded through the Randa rockslide laboratory and combined several conceptual and numerical models in terms of the tensile and shear mechanisms of slope failure [17]. Shiotani introduced a prospective method to install the AE sensor in a rock slope to evaluate the slope stability [18]. Spillmann et al. established a seismic monitoring to detect active faults of landslides [19]. Numerous studies have investigated the relationship between rock rupture events and mechanical parameters based on the notion that the AEs and damage variables are consistent. Several researchers introduced damage variables into damage mechanics to derive the relationship between the number of AEs and the damage variable and to study the mechanical properties of rock materials during the progression from microscopic damage to macroscopic rupture [20]. However, a comprehensive approach that could combine the effect of MS damage and numerical modelling to analyse the rock slope stability is rarely discussed.

This study presents a practical application of MS monitoring for stability assessment of the excavated rock slope at the Dagangshan hydropower station, Southwest China. The brief description of the right bank slope of the hydropower station is presented in Section 2. In Section 3, the MS activity characteristics of the right bank slope are described, including the MS monitoring system and tempospatial distribution of MS events. Section 4 focuses on the stability analysis of rock slope considering the effects of MS data. The conclusions are followed in Section 5.

\section{Brief Description of the Right Bank Slope of the Dagangshan Hydropower Station}

The right bank slope of the Dagangshan hydropower station is up to $700 \mathrm{~m}$ high and is located on the Dadu River near Ya'an city $\left(29^{\circ} 58^{\prime} \mathrm{N}, 103^{\circ} 01^{\prime} \mathrm{E}\right)$, approximately $350 \mathrm{~km}$ southwest of Chengdu, Sichuan province, China. The project has a double-curvature arch dam with a maximum height of $210 \mathrm{~m}$ and a total installed capacity of 2,600 MW, which controls a drainage area of approximately $62,727 \mathrm{~km}^{2}$ or $81 \%$ of the total drainage area of the Dadu River. Meanwhile, it is one of the highest excavated slopes in hydroelectric constructions that are currently used along the main stream of the Dadu River. The excavation height exceeds $300 \mathrm{~m}$. The layouts of the natural slopes and the right bank slope after excavation are shown in Figure 1.

The excavated right bank slope is characterized by complex geological structures, large-scale excavation, a high stress level, and strong rock unloading. In particular, the numerous faults, dikes, unloading fracture zones, and joints, such as $\beta_{85}, \beta_{4}, \gamma_{\mathrm{L} 5}$, $\gamma_{\mathrm{L} 6}, f_{231}$, and two deep unloading belts of XL-316 and XL-915, form the major potential unstable blocks in these areas. A typical transverse section VI-VI of the right bank slope is shown in Figure 2 to provide an in-depth understanding of the complexity of the geological conditions. The unstable blocks and large scale of the excavation may result in the potential instability of the rock slope. In fact, some tensile fractures occurred at a shallow depth. This phenomenon has rarely been encountered in other hydropower projects elsewhere.

Numerous monitoring data recorded by conventional measurement apparatuses, such as multipoint extensometers and convergence gauges, were obtained at different elevations of the right bank slope. Several macrocracks occurred on the surface of the right bank slope during the continuous excavation, as illustrated in Figure 3. The similar increasing trend of the deformation of the rock slope at an elevation of 1,101 $\mathrm{m}$ was obtained by using the convergence gauges and multipoint extensometer in July 2010. The same growth shown in Figures 4 and 5 is attributed to the continuous excavation of the rock slope.

\section{MS Activities Characteristics of the Right Bank Slope}

3.1. MS Monitoring System. Macrocracking appears on the slope surface due to the accumulation of microscopic fractures in the surrounding rock mass of the excavated slope. The MS monitoring system installed on the right bank slope of the Dagangshan hydropower station was manufactured by the ESG Corporation, Canada. The system is comprised of a Hyperion digital signal processing system, Paladin digital signal acquisition system, and twenty-four uniaxial acceleration transducers installed in the boreholes drilled from the sidewalls of the tunnels inside the right bank slope, which contain sophisticated hardware and powerful software. The real-time MS monitoring system layout installed on the right slope was developed based on network technology and built on the distributed data acquisition units with central access to the online data processing system. The twenty-four acceleration sensors covering the dimensions of $600 \mathrm{~m}$ (length), $600 \mathrm{~m}$ (width), and $400 \mathrm{~m}$ (depth) were connected to four Paladins acquisition systems using the copper twisted-pair cables (Figure 6).

The four substations were connected in series to the Hyperion processing system with optical fibre cables. The twisted-pair cable, fibre optics, and radio telemetry were typically configured during the installation process for the MS monitoring systems. Once the amount of sensors to be 


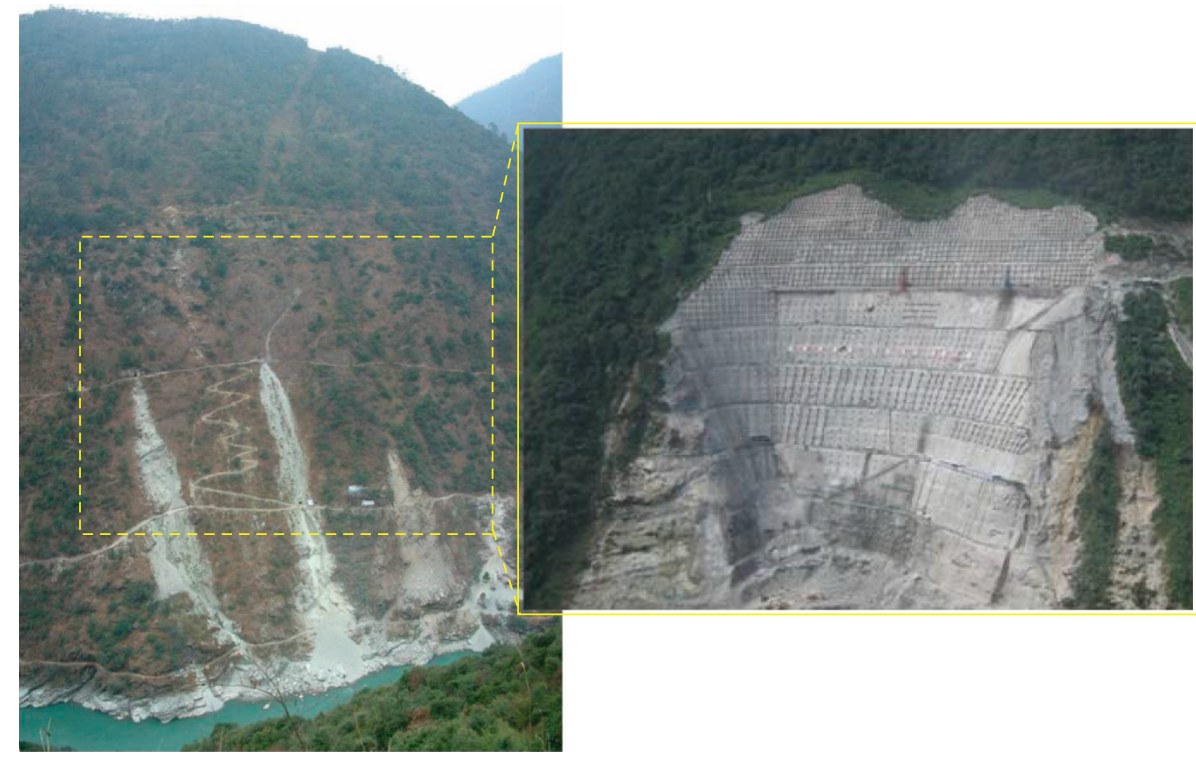

(a)

(b)

FIGURE 1: Geomorphic photograph of the right bank slope: (a) before excavation and (b) after excavation.

installed in the right bank slope was determined, a reasonable arrangement of the sensors was implemented to make full use of the MS monitoring system. The ultimate optimal arrangement of the sensor array is shown in Figure 7.

All signals were transmitted to the data analysis system installed on the right bank slope in the container at an elevation of $1,035 \mathrm{~m}$ due to geographical limitations. The data were digitized by the processing system with a sampling frequency of $10 \mathrm{kHz}$, and preliminary event detection was performed when the signals recorded by the four substations exceeded a given threshold, which was identified by the short-time average versus long-time average (STA/LTA) algorithm. The location of a seismic event wasdetermined by using the constant $\mathrm{P}$ - and S-wave velocities, which were initially estimated from artificial blasting tests.

Different wave velocities would result in different first arrival times on elastic waves to sensors; therefore, the wave velocities set in the MS monitoring system exert a great influence on positioning of MS events. The wave velocities in rock mass within the scope shall be calibrated prior to the positioning error test of the MS monitoring system. According to the provided rock sample data, the measured wave velocities were inverse calculated and calibrated using data analyse software from the ESG MS monitoring system. The average wave velocities in rock mass are determined as $\mathrm{P}$ wave $4400 \mathrm{~m} / \mathrm{s}$ and $\mathrm{S}$ wave $2540 \mathrm{~m} / \mathrm{s}$. The detailed specification can be found in [21]. An event can be located by the first $\mathrm{P}$-wave arrivals at 4-24 sensors and S-wave arrivals at 1/4-1/2 based on the simplex algorithm [22]. Moreover, the system can evaluate seismic source parameters, such as the energy index, apparent stress, magnitude, and apparent volume.

3.2. Tempospatial Characteristics of Microseismicity. The MS monitoring system was established on the right bank slope of the Dagangshan hydropower station to analyse the cause of microcracks in the rock slope subject to excavation. MS monitoring is a $3 \mathrm{D}$ and real-time monitoring technique, and it has been improved with the rapid progress of computer and data acquisition technology compared with traditional instrumentations. The MS monitoring system installed at the Dagangshan hydropower station was first adopted to investigate the macrocracks subject to the continuous excavation of the rock slope [21]. After more than one year of continuous monitoring and analysis, a total of 1,337 seismic events with $M_{\mathrm{w}}$ values ranging from -2.0 to -0.2 were detected along the right bank slope.

Figure 8 shows the correlation between the accumulative energy release and occurrence frequency of MS events. The daily frequency of MS events ranges from 1 to 10, with small bursts every 3-5 days. The mean frequency between February 25 and October 10, 2011, was approximately 10 events per day. The majority of the events were recorded during excavation. On-site observation and analysis indicated that MS activities were caused by stress redistribution in the deep slope subject to continuous excavation. The frequency of the MS events increased drastically after blasting excavation. In addition, there was no MS signal during the period from December 1, 2010, to February 20, 2011, because there was no excavation activity during the Chinese Spring Festival. After the break period, the recovery of excavation on the rock slope resulted in an increased number of MS events. Many MS events were recorded in May 2011 with continuous excavation of the right bank between 1,135 $\mathrm{m}$ and 1,240 $\mathrm{m}$. The number of recorded MS events decreased significantly after the excavation ceased in September 2011. The histogram of recorded MS events illustrates that the MS quantity is clearly attributable to the excavation unloading. The stress redistribution during the rock slope excavation is the primary source of the rock slope stability. The accumulative trend of seismic events is in good agreement with the rock slope excavation, as illustrated in Figure 8. 


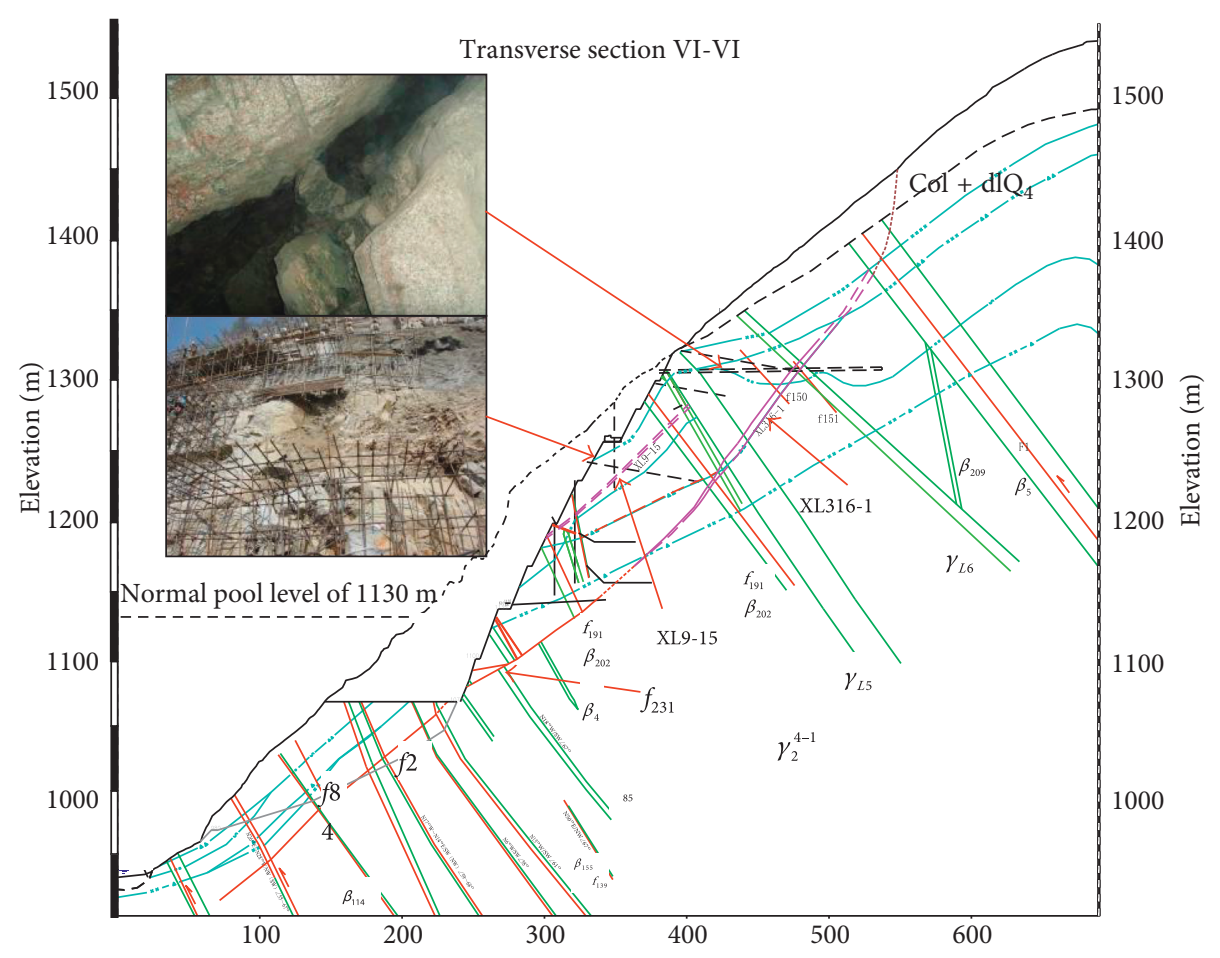

FIGURE 2: Geomorphic layout of the typical transverse section VI-VI of the right bank slope [20].

Figure 9 shows the spatial distribution of MS events recorded between May 4, 2010, and September 30, 2012. The figure highlights the distribution and migration characteristics of microfracture clusters in the deep rock mass of the right bank slope. Figure 9(a) shows that the majority of MS events occurred along faults XL-316 and $f_{231}$ and at elevations between 1,070 and $1,255 \mathrm{~m}$, thus confirming the relationship between MS events and geological structures. Furthermore, MS event clusters were mainly concentrated in the preexisting geological structures.

Figure 9(b) shows that the seismic deformation has a close correlation with the preexisting geological structures, such as faults XL-316 and $f_{231}$. The maximal seismic deformation is mainly located along the aforementioned faults. The seismic deformation is prominent in the areas of preexisting faults and man-made structures. Moreover, continuous excavation may result in energy unbalance and stress redistribution in the deep rock mass of the rock slope, which will cause the movements of weak structures and slippage of the faults. Figure 9(c) shows the energy release density of MS at the rock slope subject to excavation. The maximal density of energy dissipation was located along the faults (i.e., faults XL-316 and $f_{231}$ ) in the deep rock mass, which is consistent with the spatial distribution of the seismic deformation contours (Figures 9(a) and 9(b)). Thus, the occurrence of MS event can be used to identify and delineate the activated geological structures. The energy release mainly concentrates on the potential sliding surface, approximately $80 \mathrm{~m}$ away from the excavated slope surface.

The excavation-induced deformation can be estimated through the location, time, energy release, and scalar seismic moment magnitude of MS events. The monitoring results show that there is a close correlation between MS frequency and its accumulated energy release, which can be used to quantify the extent of damage to rock mass inside the rock slope. This in turn allows the identification and determination of the potential fracture regions and sliding surface in the excavated slope and thereby forecasts the slope failure.

Clear unloading effects are associated with stress redistribution, which results in the deterioration of the mechanical properties of the rock mass. Therefore, the strain increasingly adjusts due to rock mass degradation, which in turn generates macrocracks on the rock slope surface. Numerous investigations and laboratory tests have demonstrated that the mechanical parameters (i.e., elastic modulus, cohesion, and internal friction angle) of the rock mass in the damage zone show a marked decrease compared with the macromechanical properties before excavation $[23,24]$. Energy release inevitably occurs in the form of seismic signals before its irreversible damage. Seismic signals, which include abundant information about the internal changes of rock mass, can be captured and analysed. Therefore, the MS monitoring system is used to determine the spatial location and magnitude of MS events through seismic wave information and to estimate the development of nonlinear strain regions induced by MS activity. The results can explain the macrocracking phenomena on the excavated slope surface. Furthermore, they can provide a new approach to investigate spatial fracture patterns induced by excavation and forecast the stability of the excavated slope. In addition, the MS monitoring results can be used for an in-depth analysis of the failure characteristics of the excavated slope. 


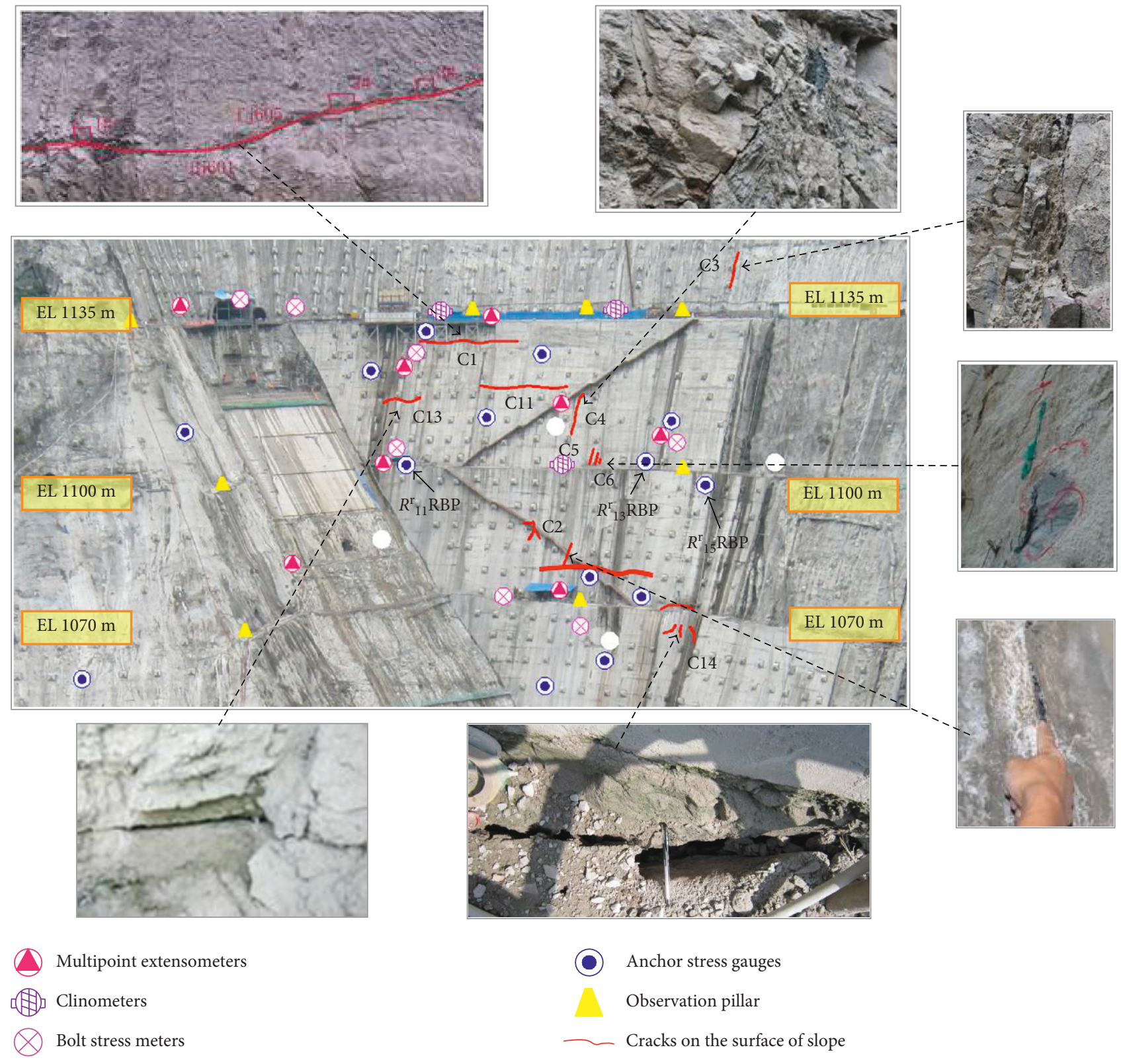

FIGURE 3: Macroscopic crack positions and layout of conventional monitoring instruments (different symbols denote different surveying instruments and the solid lines represent cracks).

Excavation-induced MS damage leads to the formation of cracks on the rock slope surface. Figure 10(a) shows that the MS events with a large magnitude and high energy mainly focus on the locations near the large cracks on the slope surface. In contrast, the MS events with a small magnitude and low energy typically concentrate along the small cracks. With further excavation, the scope of the damage zone will gradually expand. The macrocracks on the slope surface are formed by the accumulation of tiny fractures in the deep rock mass of the rock slope, as shown in Figure 10(b). Those small fractures are mainly caused by excavation unloading. The successive appearances of the macrocracks indicate the gradual evolution of damage in the rock slope. A series of tiny fractures gradually evolve and finally lead to macroscopic damage and deformation, as illustrated in Figure 10. The contours of seismic deformation in the selected periods along with the statistical analysis results can provide some information to understand the fracturing behaviour inside the rock slope (Figures 9 and 10). Thus, the MS monitoring system can offer a 3D visualization of rock mass damage and provide valuable information to understand the microcracking behaviour in the deep rock mass of the rock slope.

\section{Stability Analysis of the Rock Slope Considering the Effects of MS Data}

4.1. Description of the RFPA ${ }^{3 D}$-Centrifuge Method

4.1.1. RFPA ${ }^{3 D}$ Code. Based on RFPA ${ }^{2 \mathrm{D}}$, the $\mathrm{RFPA}^{3 \mathrm{D}}$ code was developed by considering the deformation of an 


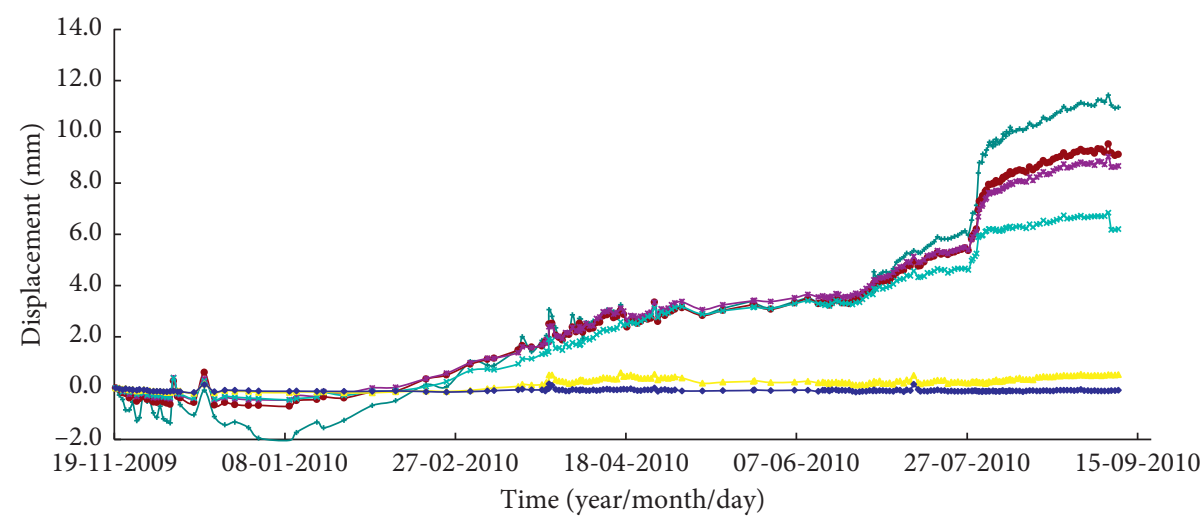

$$
\begin{aligned}
& -0+8 \\
& \text { - } 0+25.5 \\
& \longrightarrow-0+41.87 \\
& 0+53.05 \\
& -0+33.27 \\
& \rightarrow 0+63.95
\end{aligned}
$$

FIGURE 4: Displacement recorded by the convergence gauge with six points at the exploratory heading PD314 of the right bank slope (the numeral (e.g., $0+8 \mathrm{~m}$ ) represents the distance away from the audit of PD314) [20].

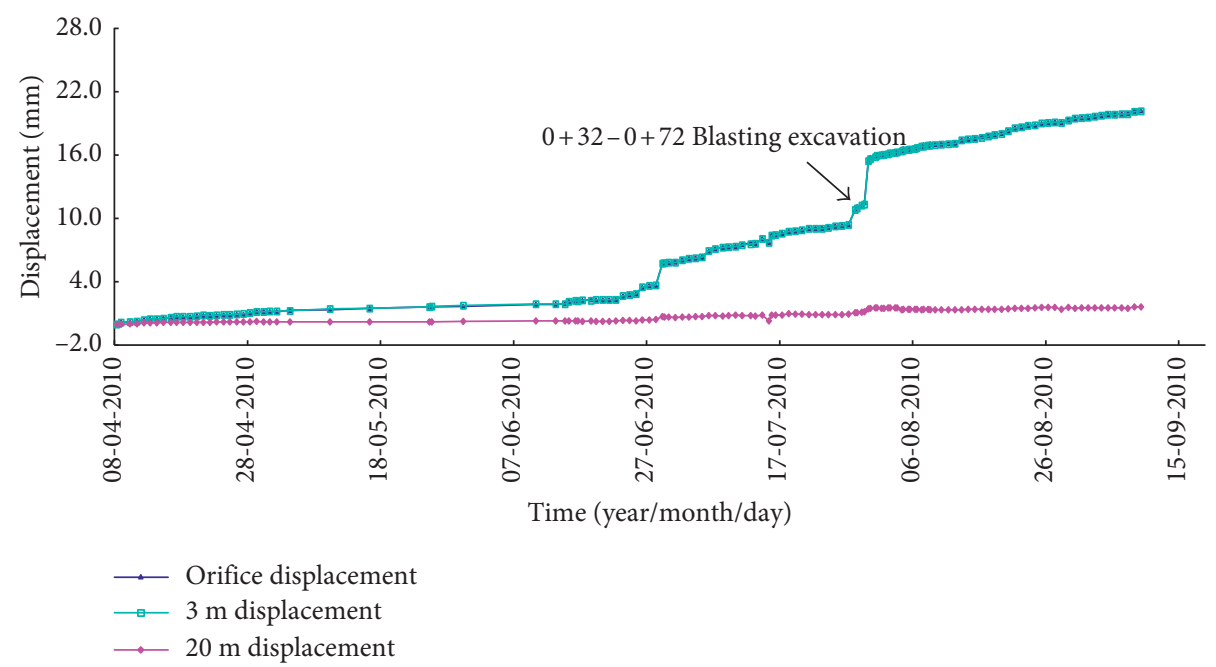

FIGURE 5: Absolute displacement recorded by the multipoint extensometer $\mathrm{M}^{3}{ }_{12 \mathrm{RBP}}$ at the dam longitudinal $0+68.5$ at an elevation of $1,075 \mathrm{~m}$ of the dam foundation [20].

elastic material containing an initial random distribution of microfractures $[25,26]$. The mechanical parameters of the model elements are assumed to follow the Weibull distribution, which includes the statistical variability of the bulk failure strength in the RFPA code. In the elastic damage mechanics, the elastic modulus of the element may decrease gradually as the damage expands until the stress increases to the threshold value. The elastic modulus of the damaged element can be expressed as follows [26]:

$$
E=(1-\omega) E_{0}
$$

where $\omega$ is the damage variable, $E$ is the elastic modulus of the damaged material elements, and $E_{0}$ is the elastic modulus of the undamaged elements. $E, E_{0}$, and $\omega$ are all scalars $[27,28]$.
4.1.2. $R F P A^{3 D}$-Centrifuge Method. Recently, an equivalent method for mechanical analysis in geotechnical engineering was provided by centrifuge modelling. Some achievements have been obtained in mining and civil engineering projects $[29,30]$. To develop a powerful and effective alternative approach, we have implemented the fundamental principles of centrifuge modelling in the $\mathrm{RFPA}^{3 \mathrm{D}}$ program, thus forming the RFPA ${ }^{3 \mathrm{D}}$-centrifuge code.

In this code, the stress field in the mesoscopic elements is obtained by adopting the FEM. To simulate centrifuge loading, the mass density of mesoscopic elements is increased gradually. The constitutive law of the mesoscopic elements is described via elastic and elastic damage mechanics. The ultimate tensile strain and envelope in the Mohr-Coulomb criterion are used as failure thresholds [28].

In centrifuge experiments, volumetric force, which is an artificial simulation of gravitational force, is added to 


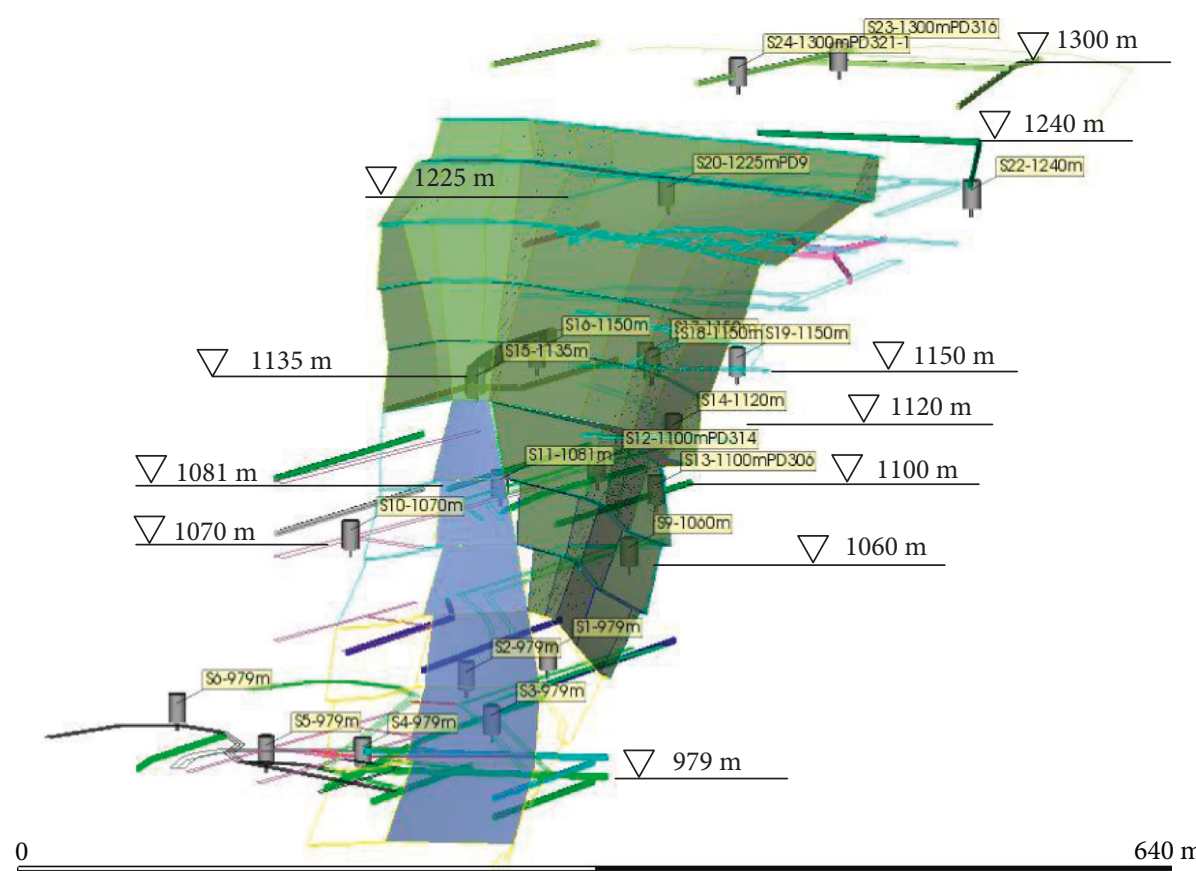

FIgURE 6: Hyperion digital signal processing system of the MS monitoring system.

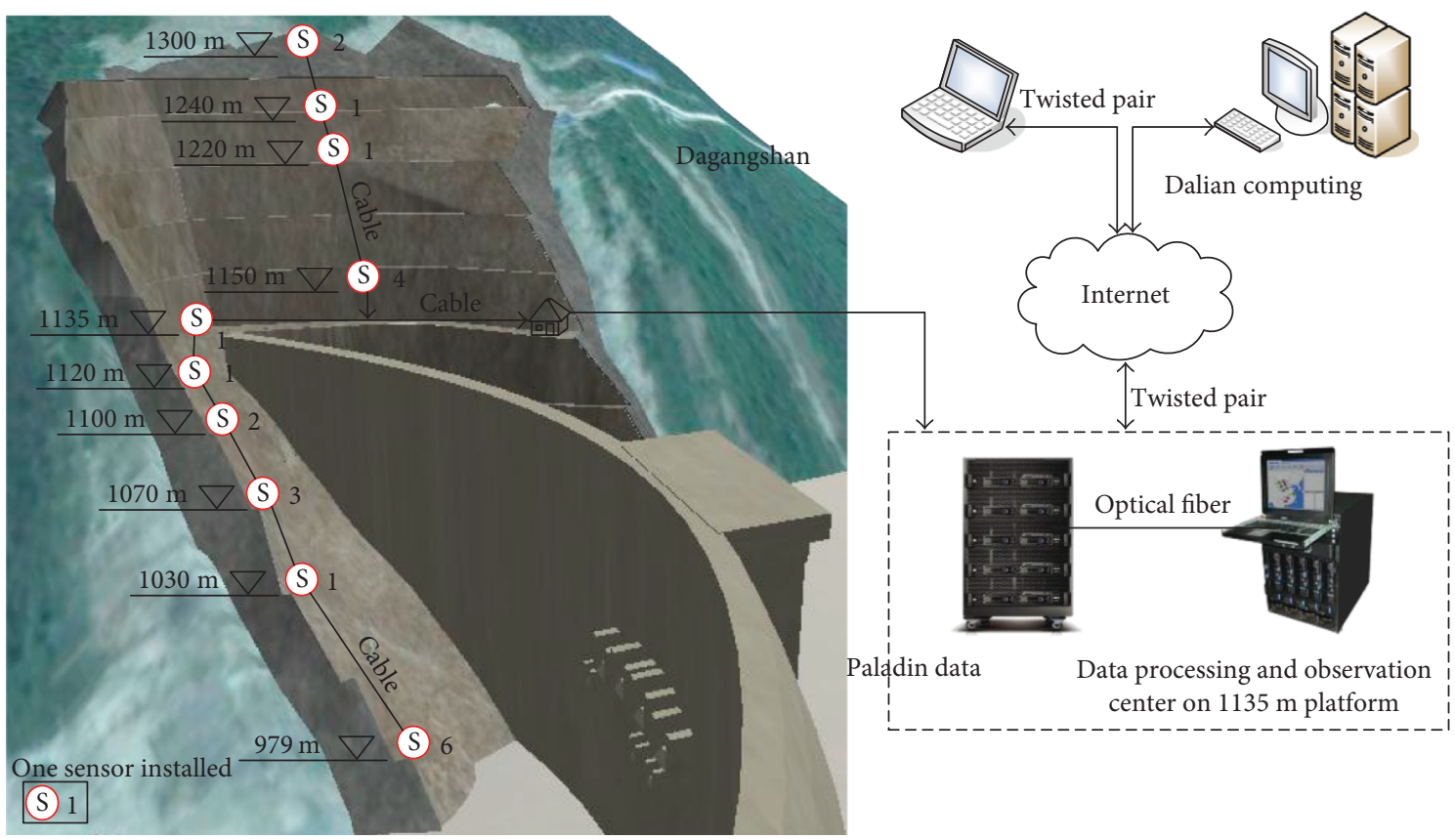

FIgURE 7: Topological graph of MS monitoring network in the right bank of the Dagangshan hydropower station.

a geotechnical model via high-speed rotation of a centrifuge. Volumetric force is used to determine the security coefficient and observe failure patterns because it can reflect the characteristics of the mechanical behaviour. The geometrical size of the original model is $n$ times the scale of its current body. The weight of the original body is defined as $\gamma_{\mathrm{p}}=\rho g$, where $g$ represents the gravitational acceleration and $\rho$ the density of rock mass. The specific weight for the model is $\gamma_{\mathrm{m}}=\rho \mathbf{a}$, in which a represents the overall acceleration vector. In accordance with the condition that the model and its original body should experience the same stresses, that is, $\sigma_{\mathrm{p}}=\sigma_{\mathrm{m}}$, it conforms to the equation, which is $\rho g h_{\mathrm{p}}=\rho \mathbf{a} h_{\mathrm{m}}$. Then,

$$
\alpha=\left(\frac{h_{\mathrm{p}}}{h_{\mathrm{m}}}\right) g=n g .
$$




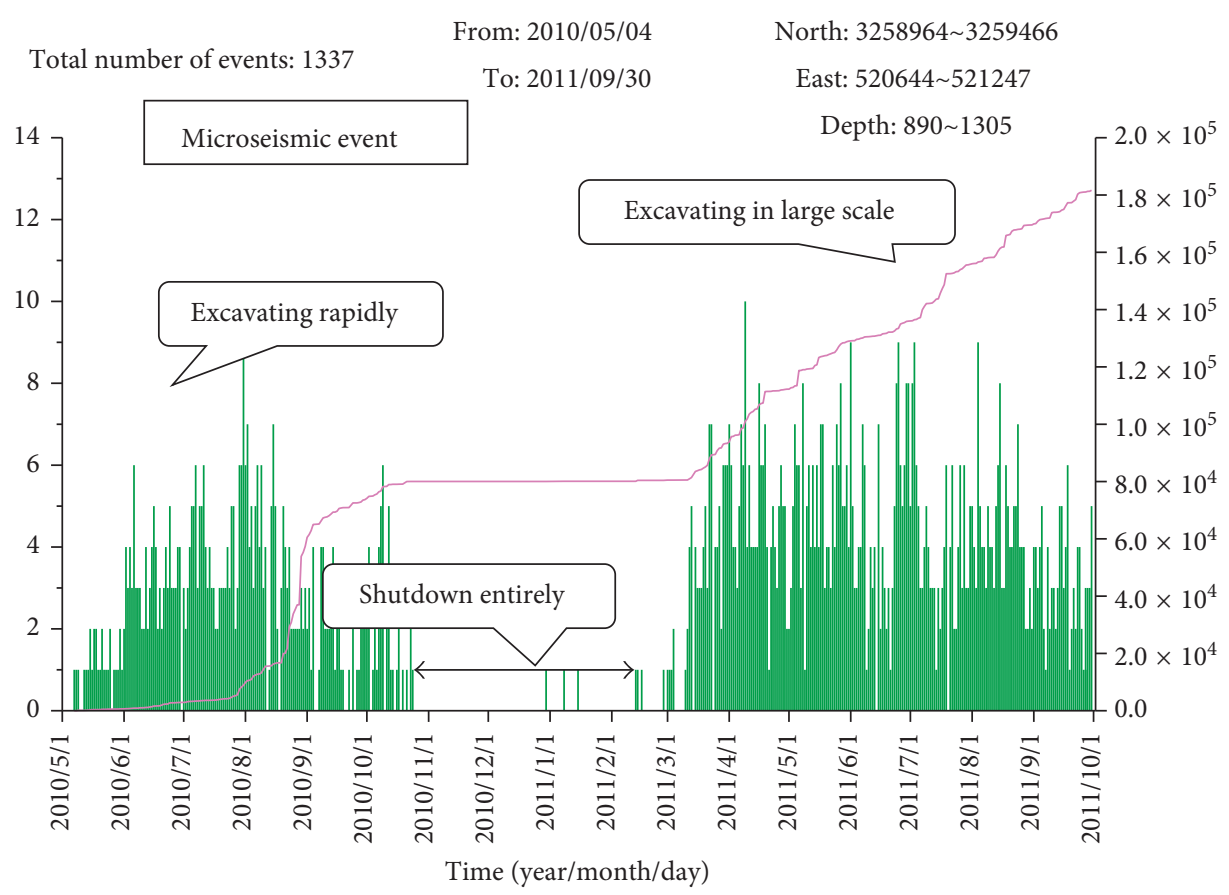

FIgURE 8: Correlation among the accumulative energy release, activity rate, and time of MS events.

In the present study, to establish the model, the aforementioned fundamental principles of centrifugal loading are introduced to represent the failure process and safety factors. The self-weight of the basic mesoscopic elements increases gradually and linearly according to a specified step size. The balance between internal and external forces is identified by performing an iteration calculation at each step. With selfadaptive loading, the failure analysis will not stop until the occurrence of macroscopic failure in the rock slope. When the number of failure elements reaches the maximum, the numerical calculation is able to identify the sliding failure surface. The ratio of the self-weight of an element upon failure to its initial weight is defined as the safety factor $K$ [24]:

$$
K=\frac{\gamma+\gamma\left(S_{\text {step }}-1\right) \Delta_{\mathrm{g}}}{\gamma}=1+\left(S_{\text {step }}-1\right) \Delta_{\mathrm{g}}
$$

where $S_{\text {step }}$ is the loading step, where the number of the failed elements reaches the limit, $\Delta_{g}$ represents the centrifuge coefficient, and $\gamma$ is the material unit weight.

\subsection{Rock Mass Degradation Constitutive Considering the} Effect of MS Damage. Energy dissipation is a vital characteristic of rock failure. Rock mass damage and strength degradation are typically related to energy dissipation, which can reflect the reduction in rock mass strength. The cohesion of the rock mass element is assumed to be lost completely provided that the damage quantity inside a rock mass element reaches the maximum after specific energy dissipation. Rock mass deformation and failure are related to the synthetic result of energy dissipation and energy release, which is the stress state of the rock mass element and lithology. Energy release is the intrinsic cause of failure of the rock mass, whereas energy dissipation induces rock mass damage and causes the degradation of material properties and strength [31].

In an MS event, the ratio of seismic energy $(\Delta \bar{U})$ to the total energy release $(\Delta U)$ during the microfracturing of the rock mass can be defined as the seismic efficiency $\eta$, that is,

$$
\eta=\frac{\Delta \bar{U}}{\Delta U}
$$

where $\eta$ is typically calculated from the ratio of radiation energy recorded by a MS monitoring system to the total energy of rock microfracture, equalling 0.1 and 1 , respectively. The seismic efficiency at the right bank slope of the Dagangshan hydropower station can be obtained by comparing the seismic wave energy with the total energy released by explosive charges during the blasting tests. For simplicity, the radiation energy and loss of heat energy are ignored. The energy released from the blasting site is transformed completely into elastic wave energy in the rock mass.

Based on the aforementioned rock mass mechanical parameters revised by the energy damage criterion, 1,587 rock blasting events were selected from the beginning of MS monitoring on May 4, 2010, until the end of the slope excavation on September 2, 2011. Statistics of the seismic source parameters of the blasting events were recorded by the MS monitoring system, as shown in Table 1 . The total energy of each blasting event is $216,000 \mathrm{~kJ}$ using \#2 rock emulsion explosive with a charge of $72 \mathrm{~kg}$ for each blast [32]. The ratio of the mean seismic radiation energy (647 J) recorded by the MS monitoring system to the total energy was determined to be approximately $0.003 \%$, which represents the equivalent seismic efficiency on the right bank slope of the Dagangshan hydropower station.

The releasable strain energy $U^{\mathrm{e}}$ of a rock mass element can be calculated as follows: 


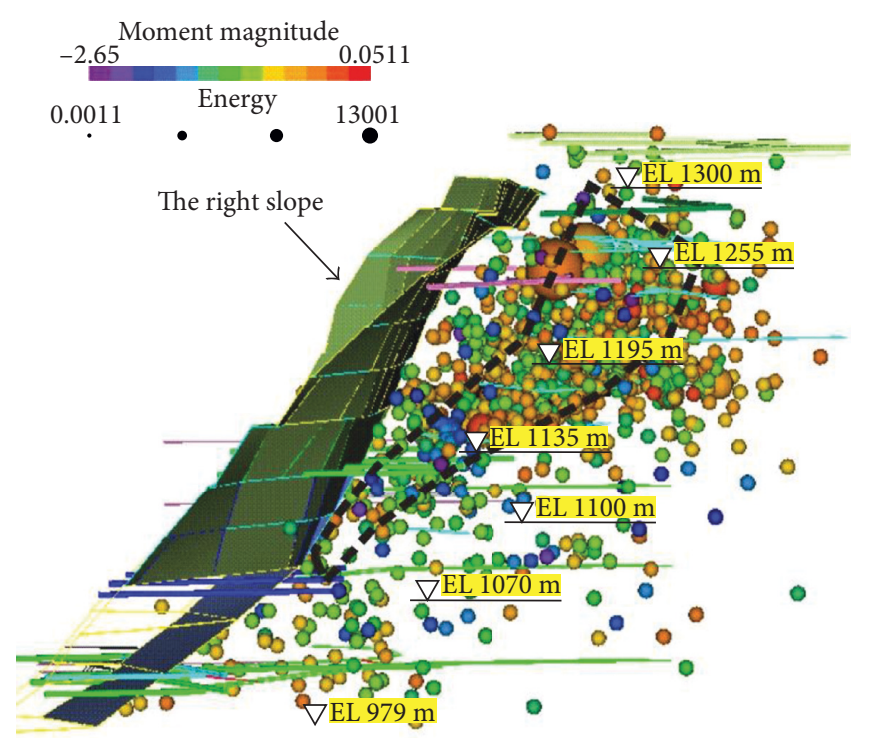

(a)

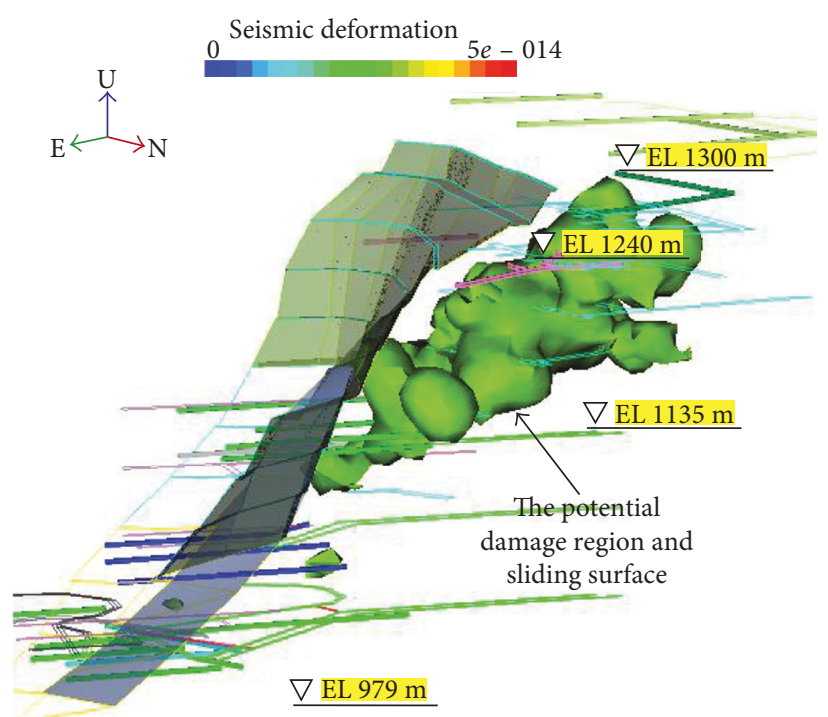

(b)

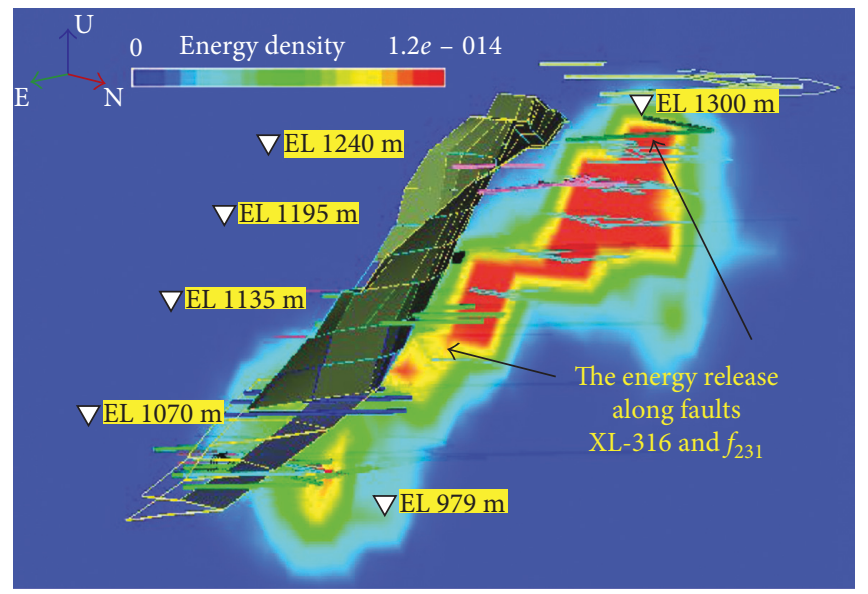

(c)

Figure 9: (a) Cross-sectional view of the spatial distribution of MS events recorded between May 2010 and May 2012 during slope excavation, (b) north-east plane of the seismic deformation, and (c) north-east plane of the energy release density contours. Different colours represent different quantities of energy dissipation density per unit volume.

$$
U^{\mathrm{e}}=\frac{1}{2 E_{0}}\left[\sigma_{1}^{2}+\sigma_{2}^{2}+\sigma_{3}^{2}-2 v\left(\sigma_{1} \sigma_{2}+\sigma_{2} \sigma_{3}+\sigma_{1} \sigma_{3}\right)\right] .
$$

A rock mass damage variable $D$ can be defined as the ratio of the assigned energy $\Delta U$ of the rock mass element based on the seismic radiation energy to the total releasable elastic strain energy $U^{\mathrm{e}}[31]$ :

$$
D=\frac{\Delta U}{U^{\mathrm{e}}}
$$

Substituting (5) into (6) yields

$$
D=\frac{2 E_{0} \Delta U}{\sigma_{1}^{2}+\sigma_{2}^{2}+\sigma_{3}^{2}-2 v_{0}\left(\sigma_{1} \sigma_{2}+\sigma_{2} \sigma_{3}+\sigma_{1} \sigma_{3}\right)},
$$

where $E_{0}$ and $v_{0}$ represent the initial elastic modulus and Poisson's ratio of the rock mass element, respectively. $\sigma_{i}$ $(i=1,2,3)$ represents the three principal stresses acting on the rock mass element.
Therefore, the corresponding cohesion $c_{\mathrm{r}}$ and elastic modulus $E_{\mathrm{r}}$ of the rock mass element, considering the seismic energy dissipation, can be expressed as

$$
\begin{aligned}
& c_{\mathrm{r}}=(1-D) c_{0}, \\
& E_{\mathrm{r}}=(1-D) E_{0},
\end{aligned}
$$

where $c_{0}$ and $E_{0}$ represent the initial cohesion and elastic modulus of the rock mass element, respectively. Numerical simulation of the rock slope excavation can be undertaken to consider the effects of MS damage by degrading the mechanical properties of the rock mass according to the damage variable $D$.

To determine the effect of MS damage on rock slope stability, the following assumptions must be made regarding the damage to the rock mass element [24], which are also the limitation of this study: 


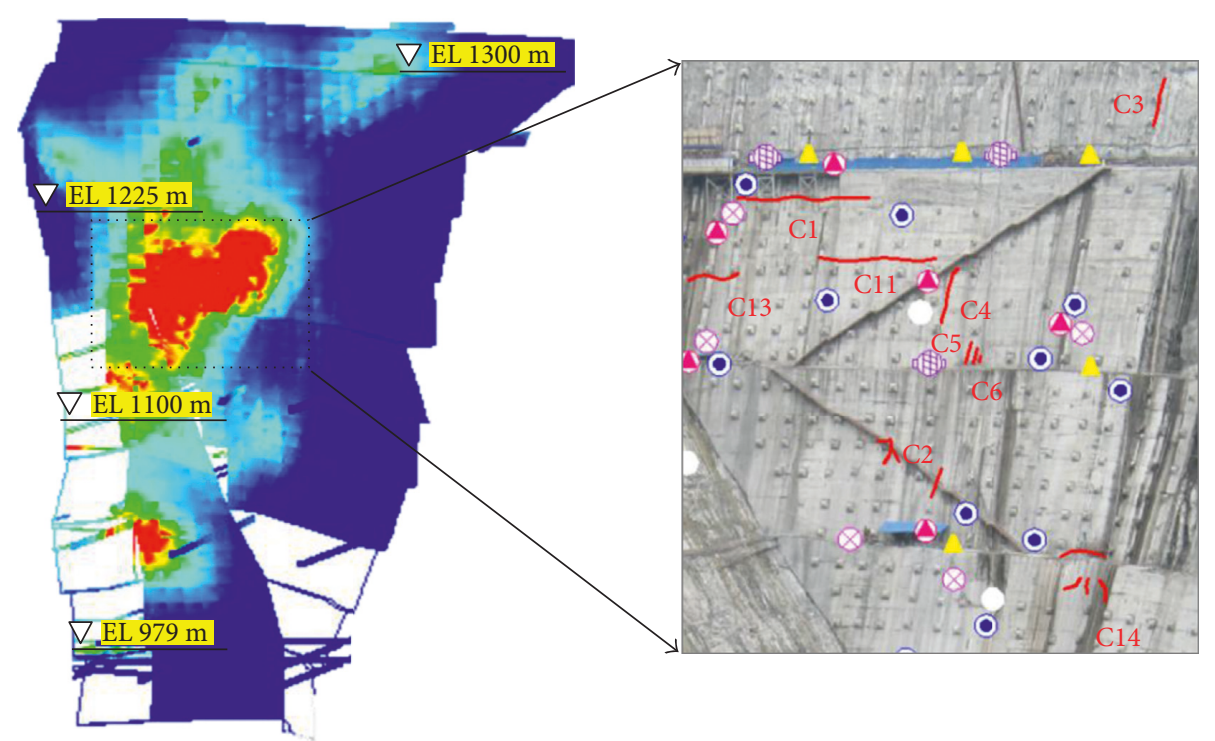

(a)

(b)

FIgURE 10: (a): Excavation-induced seismic deformation on the slope surface and (b) on-site photograph of the cracked region on the slope surface after excavation between elevations of $1,100 \mathrm{~m}$ and 1,225 m.

(1) The rock mass is homogeneous. The effects of energy loss on the mechanical parameters of the rock mass due to rock failure are considered.

(2) The energy loss induced by the seismic events affects only the corresponding areas of interest in the 3D FEM model. The corresponding FEM grid cells are automatically searched according to the $3 \mathrm{D}$ coordinates of the seismic events. The seismic energy is evenly distributed in the grid cells within the area of the seismic source size, and the mechanical parameters of the rock mass are revised according to the proposed energy damage criterion.

(3) The deformation of the rock mass elements is elastic in the area of the seismic source size.

Based on these assumptions, a flowchart is generated to illustrate the "feedback analysis" of the rock slope stability considering the effect of MS damage, as shown in Figure 11.

4.3. Numerical Modelling. The 3D model simulates the topography and prominent structures of the two large unloading fissure zones XL-316 and XL-915 and fault $f_{231}$. The model covers $690 \mathrm{~m}$ across the river, $400 \mathrm{~m}$ along the river, and a height of $1,060 \mathrm{~m}$ from the upstream area to the downstream area, as shown in Figure 12(a). Different colours represent different mass models, as shown in Figure 12(b). The mechanical parameters are listed in Table 2 [33]. The model implemented in RFPA $^{3 \mathrm{D}}$ uses a bottom-up technique that subdivides the $3 \mathrm{D}$ model into $1,118,264$ hexahedron elements and 1,153,843 nodes, as shown in Figure 12(c).

The model conducts encryption processing on the shallow slope. The number of elements in the shallow slope comprises up to approximately $93 \%$ of the 3D model. Normal constraints are applied in the computation field. Fixed hinges are used for the bottom boundary, and the slope surface is free. The centrifugal load coefficient in the calculation is 0.005 . The finite element model entities and mesh subdivision are presented in Figure 12. The C programming language is used to convert the interface routine data by extracting the nodes and units from the ANSYS model and inserting them into the RFPA ${ }^{3 \mathrm{D}}$ code.

\subsection{Simulation Results}

4.4.1. Rationality Analysis of Numerical Simulation. Figure 13 shows the correlation between the MS energy density of the Dagangshan right bank slope under excavation unloading obtained from the MS system and numerical simulation results and the $\mathrm{AE}$ distribution calculated by RFPA $^{3 \mathrm{D}}$. The MS energy density can be used to characterize the location and strength of MS events in rock mass, which can be used to delineate potential danger zones in the bank slope. The formation of potential slip surfaces during the slope excavation reveals that the slope will fail by overall buckling and confirms that the weak structural surface is one of the main controlling factors of the rock slope failure mode, as shown in Figure 13(a). The AEs during excavation process based on calculations from $\mathrm{RFPA}^{3 \mathrm{D}}$ are mostly distributed along the unloading fissure zone XL-316 and the fault $f_{231}$, forming a potential slip surface as shown in Figure 13(b). Weakening of the dominant structure plane from the slope top downward during excavation process is the main cause of potential slope instability. The AE accumulation zone obtained from numerical solution and the distribution of high MS density zone are highly coherent, which showed that the evolution simulation of Dagangshan right bank slope stability under excavation using RFPA $^{3 \mathrm{D}}$ did match the site monitoring results and established the model foundation of $\mathrm{RFPA}^{3 \mathrm{D}}$ slope stability analysis with MS data feedback. 
TABLE 1: Seismic source parameters of typical blasting events.

\begin{tabular}{|c|c|c|c|c|c|c|c|c|c|c|}
\hline Event & $\begin{array}{l}\text { Northing } \\
\quad(\mathrm{m})\end{array}$ & $\begin{array}{l}\text { Easting } \\
(\mathrm{m})\end{array}$ & $\begin{array}{l}\text { Depth } \\
(\mathrm{m})\end{array}$ & $\begin{array}{l}\text { Moment } \\
\text { magnitude }\end{array}$ & $\begin{array}{c}\text { Seismic } \\
\text { moment }(\mathrm{Nm})\end{array}$ & $\begin{array}{l}\text { Radiated } \\
\text { energy }(J)\end{array}$ & $E_{\mathrm{s}} / E_{\mathrm{p}}$ & $\begin{array}{c}\text { Source } \\
\text { radius (m) }\end{array}$ & $\begin{array}{l}\text { Static stress } \\
\text { drop }(\mathrm{Pa})\end{array}$ & $\begin{array}{l}\text { Apparent } \\
\text { stress }(\mathrm{Pa})\end{array}$ \\
\hline 1 & $3,259,192$ & 520,819 & 1078 & -0.93 & $1.02 E+08$ & $1.35 E+02$ & 8.95 & $6.38 E+00$ & $4.78 E+05$ & $2.30 E+04$ \\
\hline 2 & $3,259,426$ & 520,961 & 1181.7 & -0.81 & $1.08 E+08$ & $2.86 E+01$ & 31.34 & $1.24 E+01$ & $8.85 E+04$ & $4.61 E+03$ \\
\hline 3 & $3,259,230$ & 520,842 & 1060 & -1.16 & $4.80 E+07$ & $3.48 E+01$ & 3.2 & $5.39 E+00$ & $3.19 E+05$ & $1.26 E+04$ \\
\hline 4 & $3,259,244$ & 520,739 & 1062.7 & -1.34 & $1.84 E+07$ & $3.42 E+00$ & 1.72 & $5.42 E+00$ & $6.86 E+04$ & $3.23 E+03$ \\
\hline 5 & $3,259,206$ & 520,800 & 1042.7 & -0.51 & $3.32 E+08$ & $6.41 E+02$ & 10.63 & $6.78 E+00$ & $8.90 E+05$ & $3.36 E+04$ \\
\hline 6 & $3,259,197$ & 520,831 & 1083.9 & -0.88 & $8.33 E+07$ & $1.18 E+02$ & 7.71 & $3.86 E+00$ & $6.85 E+05$ & $2.47 E+04$ \\
\hline 7 & $3,259,202$ & 520,874 & 1064.3 & -1.1 & $4.84 E+07$ & $6.49 E+01$ & 10.92 & $6.66 E+00$ & $8.60 E+04$ & $2.34 E+04$ \\
\hline 8 & $3,259,402$ & 520,957 & 1171.5 & -0.87 & $8.19 E+07$ & $1.50 E+01$ & 11.25 & $1.04 E+01$ & $3.15 E+04$ & $3.19 E+03$ \\
\hline 9 & $3,259,227$ & 520,783 & 1032.9 & -0.85 & $1.58 E+08$ & $1.50 E+02$ & 7.53 & $5.93 E+00$ & $5.07 E+05$ & $1.65 E+04$ \\
\hline 10 & $3,259,304$ & 520,757 & 987.6 & -0.82 & $1.35 E+08$ & $3.75 E+02$ & 10.05 & $5.13 E+00$ & $7.75 E+05$ & $4.82 E+04$ \\
\hline 11 & $3,259,177$ & 520,855 & 1182.2 & -0.71 & $2.79 E+08$ & $1.07 E+02$ & 12.89 & $8.58 E+00$ & $2.20 E+05$ & $6.69 E+03$ \\
\hline 12 & $3,259,441$ & 520,971 & 1139.2 & -1.03 & $6.98 E+07$ & $4.37 E+00$ & 19.8 & $1.01 E+01$ & $2.62 E+04$ & $1.09 E+03$ \\
\hline 13 & $3,259,202$ & 520,790 & 1037 & -0.74 & $1.64 E+08$ & $1.82 E+02$ & 11.47 & $7.15 E+00$ & $5.44 E+05$ & $1.94 E+04$ \\
\hline 14 & $3,259,226$ & 520,804 & 1039.2 & -0.74 & $1.36 E+08$ & $2.12 E+02$ & 20.71 & $8.93 E+00$ & $3.78 E+05$ & $2.71 E+04$ \\
\hline 15 & $3,259,277$ & 520,754 & 995.3 & -0.78 & $1.64 E+08$ & $2.38 E+02$ & 21.7 & $6.46 E+00$ & $5.44 E+05$ & $2.53 E+04$ \\
\hline 16 & $3,259,193$ & 520,814 & 1074.9 & -0.83 & $1.26 E+08$ & $2.04 E+02$ & 8.55 & $8.01 E+00$ & $2.95 E+05$ & $2.81 E+04$ \\
\hline 17 & $3,259,368$ & 520,839 & 1140.6 & -1.11 & $3.83 E+07$ & $1.96 E+00$ & 8.23 & $9.36 E+00$ & $1.77 E+04$ & $8.91 E+02$ \\
\hline 18 & $3,259,206$ & 520,810 & 1047.6 & -0.24 & $7.16 E+08$ & $3.97 E+03$ & 19.87 & $8.65 E+00$ & $1.96 E+06$ & $9.66 E+04$ \\
\hline 19 & $3,259,201$ & 520,802 & 1046.7 & -0.58 & $2.62 E+08$ & $3.47 E+02$ & 35.42 & $9.18 E+00$ & $5.55 E+05$ & $2.30 E+04$ \\
\hline 20 & $3,259,303$ & 520,764 & 992.8 & -0.95 & $1.10 E+08$ & $9 E+01$ & 5.43 & $6.27 E+00$ & $3.97 E+05$ & $8.12 E+03$ \\
\hline 21 & $3,259,380$ & 520,768 & 1123.9 & -1.05 & $1.17 E+08$ & $2.53 E+02$ & 5.04 & $8.61 E+00$ & $3.24 E+04$ & $3.78 E+04$ \\
\hline 22 & $3,259,192$ & 520,808 & 1069.7 & -0.76 & $1.43 E+08$ & $1.42 E+02$ & 10.39 & $7.77 E+00$ & $3.61 E+05$ & $1.72 E+04$ \\
\hline 23 & $3,259,368$ & 520,794 & 1154.1 & -0.92 & $9.27 E+07$ & $5.56 E+00$ & 64.86 & $1.58 E+01$ & $1.29 E+04$ & $1.04 E+03$ \\
\hline 24 & $3,259,234$ & 520,781 & 1020.3 & -0.21 & $1.02 E+09$ & $5.44 E+03$ & 22.17 & $9.68 E+00$ & $1.85 E+06$ & $9.32 E+04$ \\
\hline 25 & $3,259,218$ & 520,807 & 1056 & -0.9 & $6.20 E+07$ & $8.22 E+01$ & 286.05 & $6.41 E+00$ & $3.86 E+05$ & $2.31 E+04$ \\
\hline$\vdots$ & $\vdots$ & $\vdots$ & $\vdots$ & $\vdots$ & $\vdots$ & $\vdots$ & $\vdots$ & $\vdots$ & $\vdots$ & $\vdots$ \\
\hline 1587 & $3,259,234$ & 520,813 & 1184.1 & -1.19 & $2.95 E+07$ & $1.28 E+00$ & 20.43 & $1.24 E+01$ & $2.50 E+04$ & $7.58 E+02$ \\
\hline
\end{tabular}

4.4.2. Input and Analysis of MS Parameters. The MS parameters from the monitoring system are fed into the above numerical model by a RFPA-MMS program. The actual spatial coordinates of the MS events are used to couple the model. According to the MS damage, the rock mechanical parameters are degraded to even the distribution of the seismic energy within the grid unit. Consequently, the seismic energy of each damaged rock element is characterized in space sphere units after the automatic allocation (Figure 14). Automatic searching and positioning of MS damage was performed, and the mechanical parameters of the rock elements degraded correspondingly for the numerical model. The revised mechanical parameter of the numerical model rock unit (damaged elasticity modulus $E_{\mathrm{r}}$ ) is reassigned based on the MS damage effect; thus, the degradation of mechanical parameters of rock slope and the stability analysis with the consideration of MS damage feedback were carried out.

4.4.3. Feedback Analysis Considering MS Data. The computational progressive failure process in consideration of MS damage is shown as Figure 15. Upon the completion of bank slope excavation, the computational bank slope which considered the MS damage had its first damage in the uppermiddle zone along the unloading fissure zone XL-316, as shown in Figures 15(a)-15(e). Due to centrifugal loading, damage occurs along the unloading fissure zone XL-316, and internal fault $f_{231}$ also produces an extensive damage area. The MS clustering creates a certain pattern along the potential sliding surface. When the loading reaches Step 6, unloading fissure XL-316 and internal fault $f_{231}$ are completely damaged, losing their bearing capacity and forming a sliding block with the unloading fissure zone XL-316 as the top half plane and fault $f_{231}$ as the bottom half plane. The microfractures penetrated into strips with shear failure in the intersections and exhibited a downward settlement trend (Figure 15(f)). Finally, macrodamage appears on the side slope until collapse occurs and deformation along the valley direction occurs at the toe of the excavation slope. The subsidence towards the bottom of the rock slope takes place, and macroscopic failure begins and continues gradually in Step 7 (Figure 15(g)). The upper slope mainly shows tensile failure, and the base of the slope mainly shows shear failure with slight tensile failure. The blue spheres represent tensile failure, and the red spheres show shear failure (Figure 15(h)). The instability mechanisms of the rock slope are predominantly the initiation, propagation, evolution, and failure of the potential fracture surface along the main faults or weak zones. The calculated safety factor of the rock slope is 1.03 . The safety factor of the rock slope is reduced by 0.18 (from 1.21 to 1.03 ) compared with the case without considering the MS-determined damage [34]. Therefore, the effect of rock mass damage induced by excavation is significant in the stability analysis of the rock slope. Nevertheless, the safety factor still satisfies the requirements of hydraulic design specification in China. The MS monitoring and $3 \mathrm{D}$ simulation results indicate that the main faults play a significant role in rock slope instability. The initiation, 


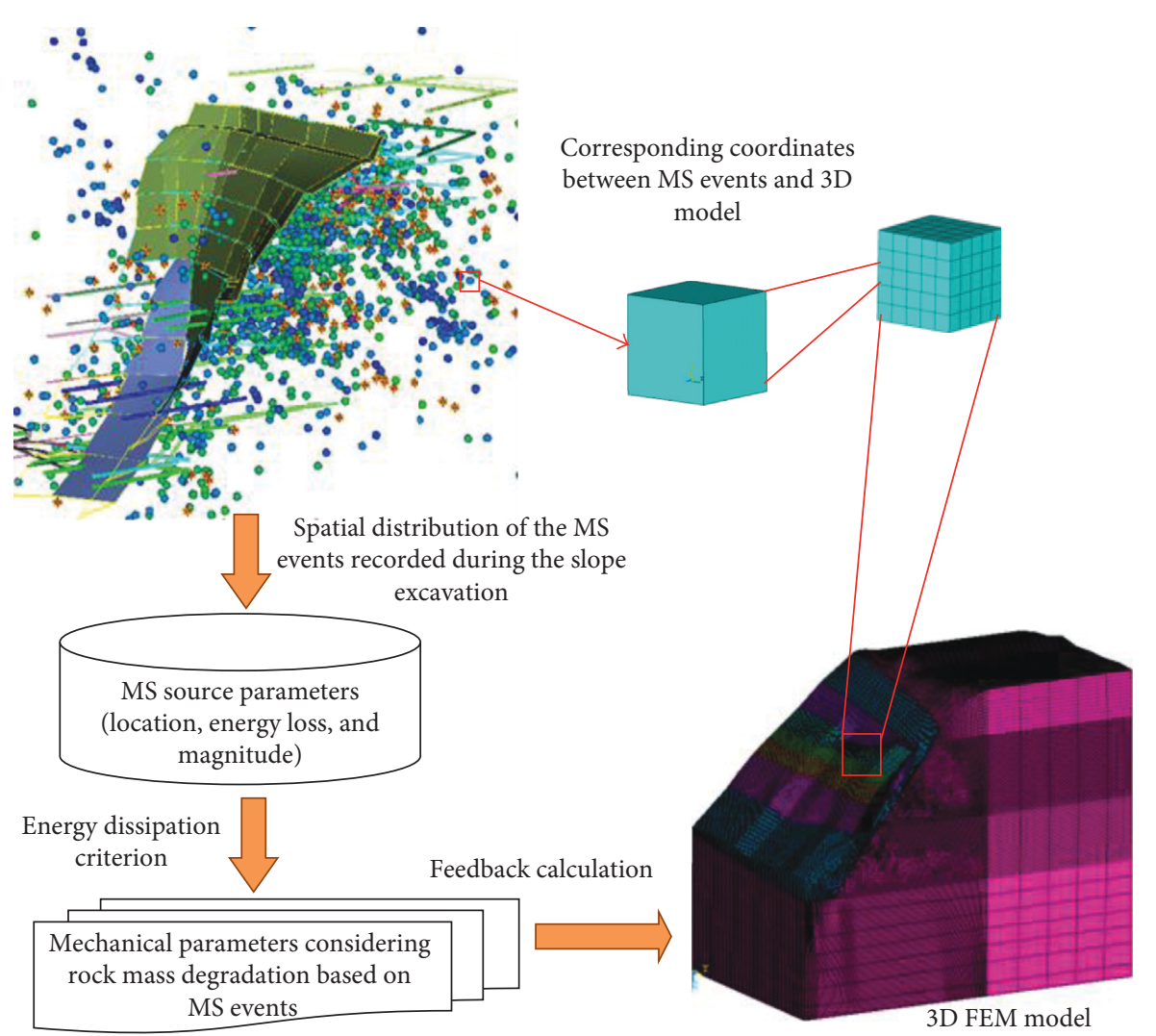

FIGURE 11: Flowchart of the back analysis of slope stability considering the effects of MS damage.

propagation, evolution, and aggregation of microcracking inside the rock slope can be identified and delineated in real time by such an integrated approach.

The rock mass parameters are updated in real time in the 3D FEM model considering the effect of MS damage. The numerical calculation of the excavated rock slope is performed through the $\mathrm{RFPA}^{3 \mathrm{D}}$ centrifugal loading method. The simulated results include the real-time safety factors considering the effect of MS damage and reproduce the $3 \mathrm{D}$ progressive failure processes of the rock slope. The results reveal the damage evolution mechanism of rock slope instability and visually reflect the potential sliding surface of the slope determining the rock slope failure mode.

\section{Conclusions}

MS monitoring provides an approach for quantifying rock mass degradation. A 3D FEM model was established based on the characteristics of MS data recorded at the right bank slope of the Dagangshan hydropower station. According to the proposed rock mass degradation criterion, the mechanical parameters of the rock mass were modified as inputs to update the properties of elements in the numerical model. The stability of the excavated rock slope was evaluated considering the MS damage effect, which is the contribution to the theory of this study. The following conclusions can be drawn:

(1) The spatial distribution of MS delineated the weak geological structures and identified the potential sliding surfaces inside the rock slope. There may be a risk of deformation on the right bank slope. The main cause of fissures in the rock slope surface was local small block deformation due to the existence of unloading fracture zone XL-316 and fault $f_{231}$.

(2) The $3 \mathrm{D}$ numerical simulation of the failure processes of the right bank slope revealed that the deep faults or weak structural planes in the rock slope played a significant role in the instability mechanism. The effects of rock mass damage and energy dissipation can be used to describe the constitutive equations and strength criterion of a rock mass. Based on the results of blasting testing events, the equivalent seismic efficiency of MS on the right bank slope of the Dagangshan hydropower station was calculated as $0.003 \%$. The safety factor of the rock slope obtained by the RFPA ${ }^{3 \mathrm{D}}$-centrifuge method was 1.03 , which was 0.18 lower than the safety factor obtained without account for MS damage. This result is a direct quantitative verification of the rock damage caused by MS events in the process of rock slope excavation.

(3) According to the numerical modelling and MS monitoring results, more attention should be paid to the junction of unloading fracture zone XL-316 and fault $f_{231}$ for the convergence and deformation situation. A basis for the safety control assessment of the dam construction and water storage phases is provided. 


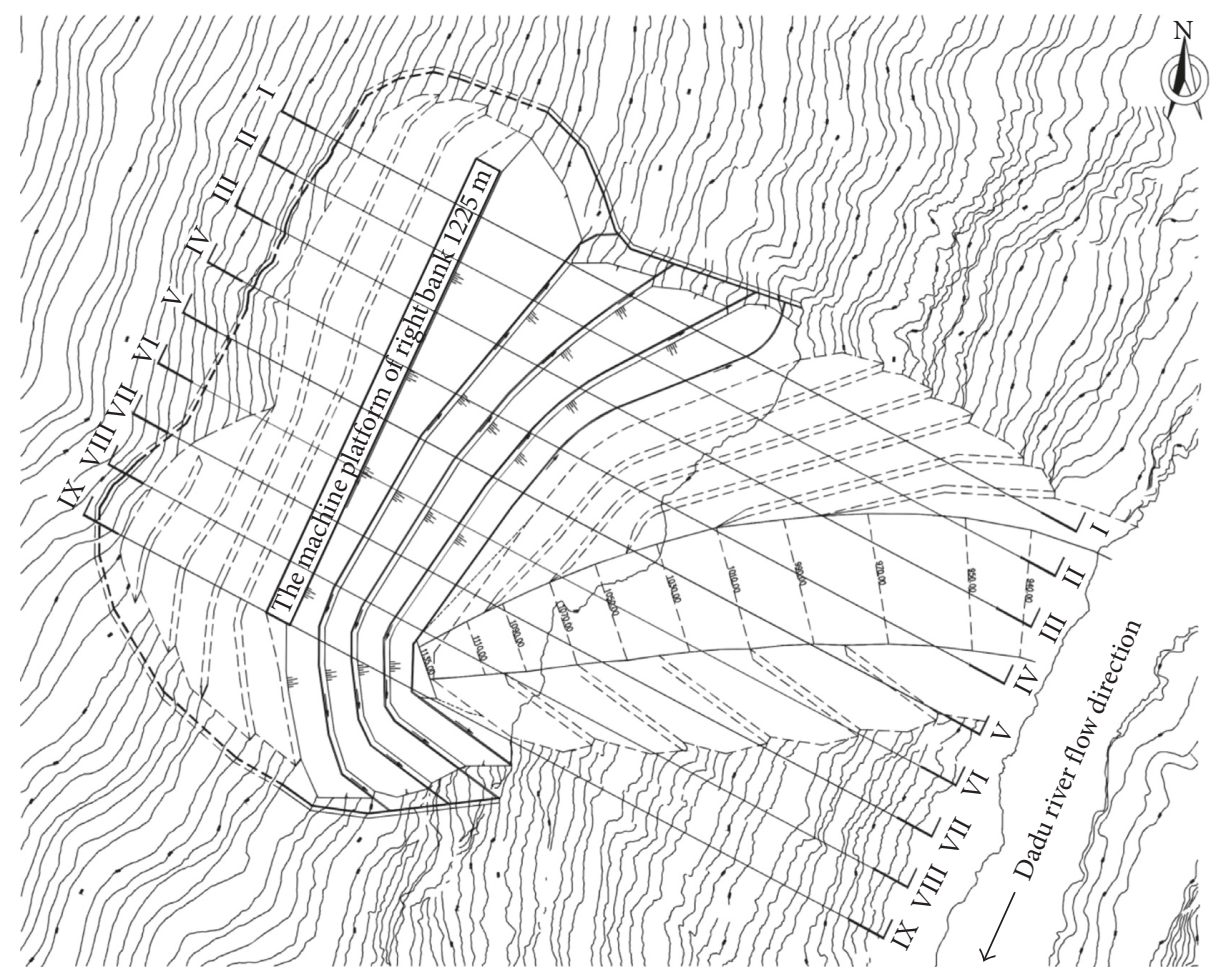

(a)

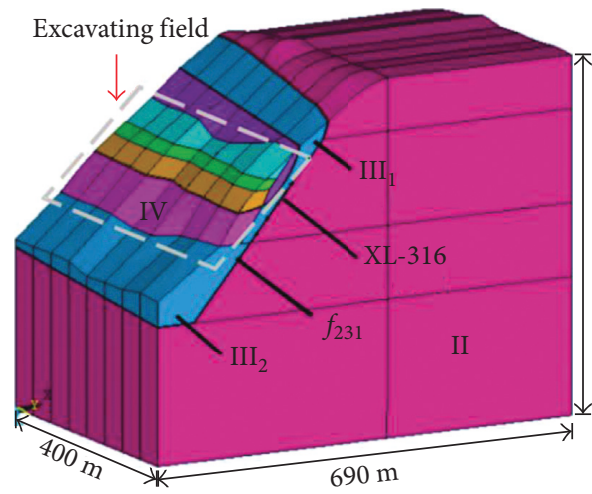

(b)

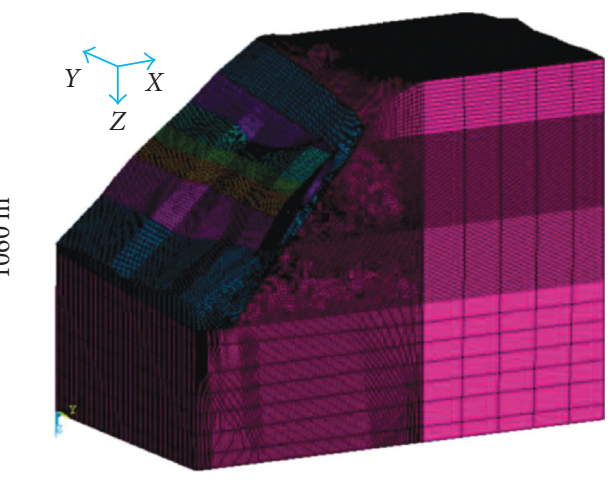

(c)

FIGURE 12: Three-dimensional numerical model and location of the main faults generated by RFPA ${ }^{3 \mathrm{D}}$ : (a) excavation design of the right bank slope; (b) physical model; (c) FEM model (the different colours in the figure indicate different mechanical parameters, such as the elastic modulus and compression strength of the rock mass).

TABle 2: Mechanical properties of the rock mass.

\begin{tabular}{lccccc}
\hline $\begin{array}{l}\text { Material } \\
\text { number }\end{array}$ & $\begin{array}{c}\text { Density } \\
\left(\mathrm{g} \cdot \mathrm{cm}^{-3}\right)\end{array}$ & $\begin{array}{c}\text { Compressive } \\
\text { strength } \\
(\mathrm{MPa})\end{array}$ & $\begin{array}{c}\text { Deformation } \\
\text { modulus } \\
(\mathrm{GPa})\end{array}$ & $\begin{array}{c}\text { Poisson's } \\
\text { ratio }\end{array}$ & $\begin{array}{c}\text { Friction } \\
\text { factor }\end{array}$ \\
\hline $\mathrm{II}$ & 2.65 & $70 \sim 80$ & $18.00 \sim 25.00$ & 0.25 & 1.30 \\
$\mathrm{III}_{1}$ & 2.62 & $40 \sim 60$ & $9.00 \sim 11.00$ & 0.27 & 1.20 \\
$\mathrm{III}_{2}$ & 2.62 & $40 \sim 60$ & $6.00 \sim 9.00$ & 0.30 & 1.00 \\
$\mathrm{IV}$ & 2.58 & $20 \sim 40$ & $2.50 \sim 3.50$ & 0.35 & 0.80 \\
$\mathrm{XL}-316$ & 2.45 & $<15$ & $0.25 \sim 0.50$ & $>0.35$ & 0.50 \\
$f_{231}$ & 2.10 & $<10$ & 0.20 & $>0.35$ & 0.00 \\
$(\mathrm{MPa})$
\end{tabular}




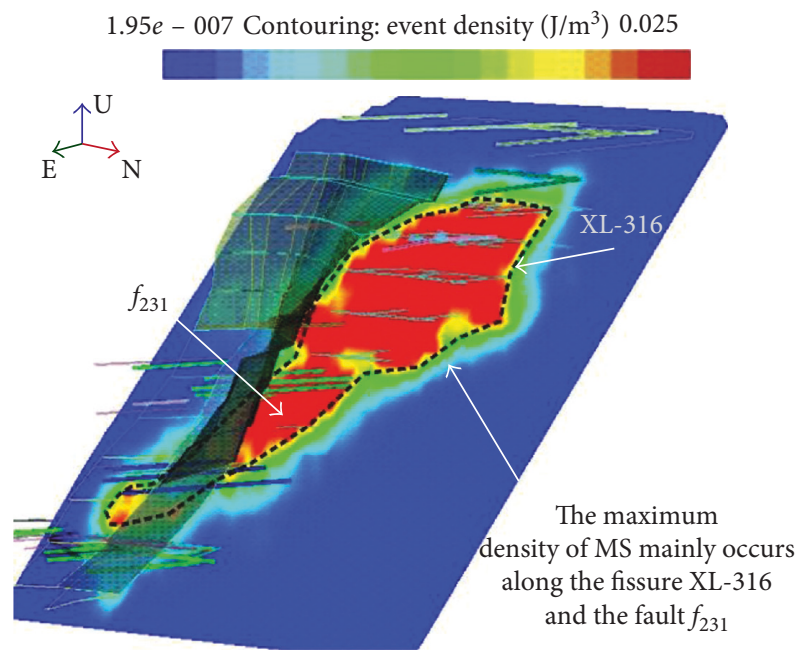

(a)

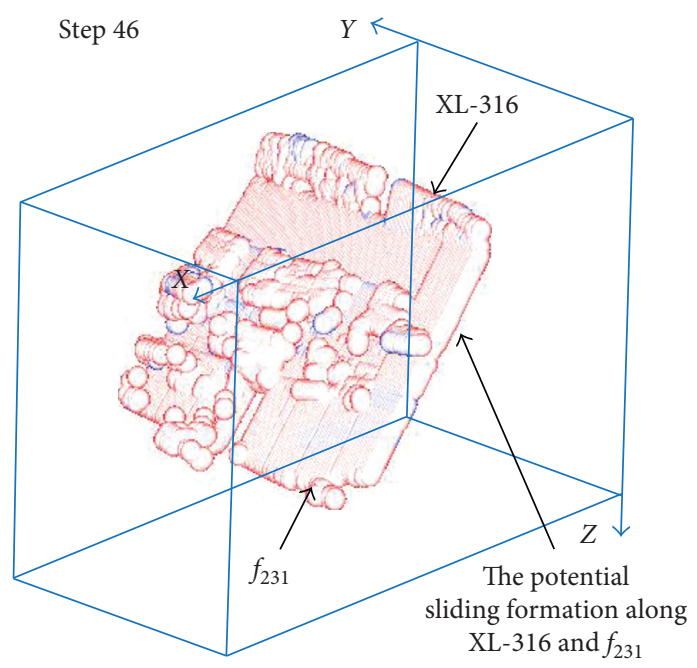

(b)

FIGURE 13: Correlation between the MS monitoring results and numerical simulation results for the right bank slope during excavation: (a) spatial MS events and (b) AE distribution obtained by RFPA ${ }^{3 \mathrm{D}}$.
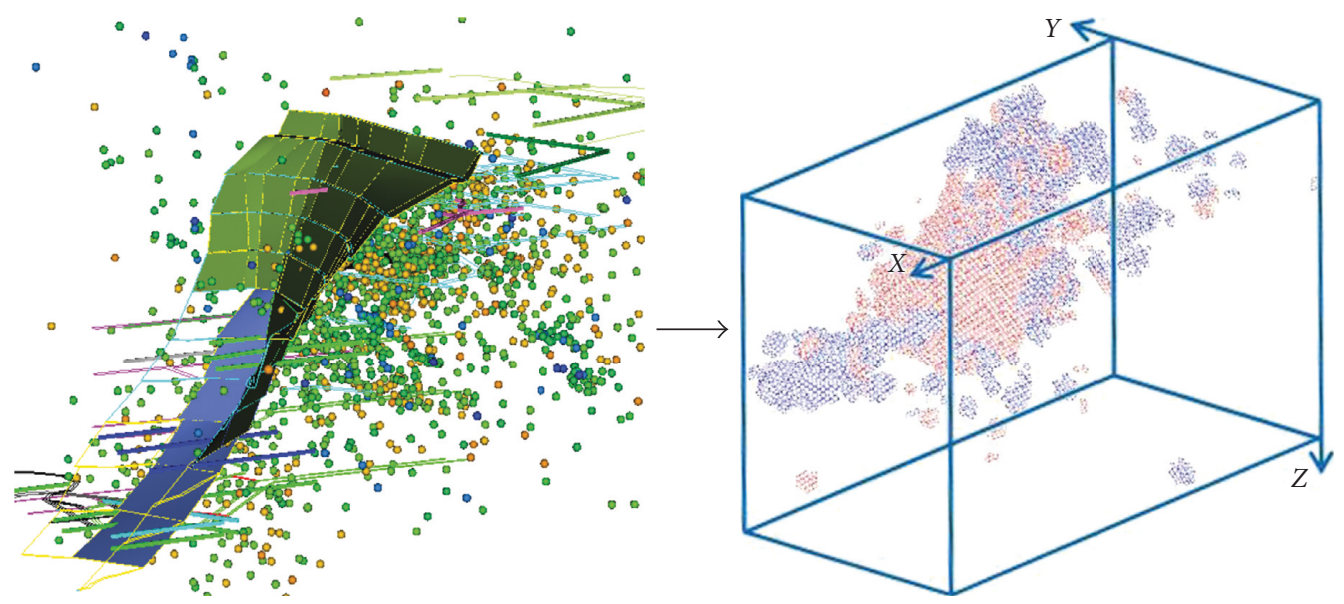

FIGURE 14: Computational domain of the back analysis of the right bank slope.

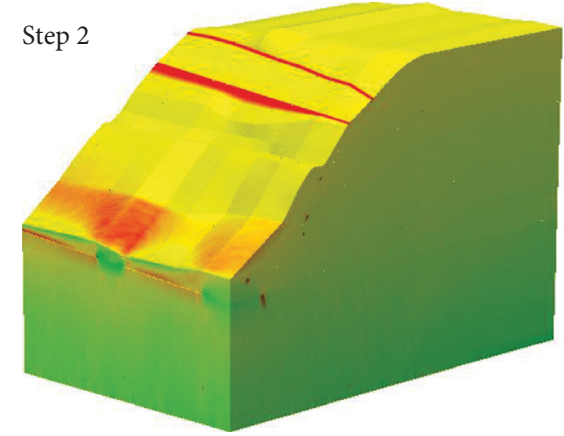

(a)

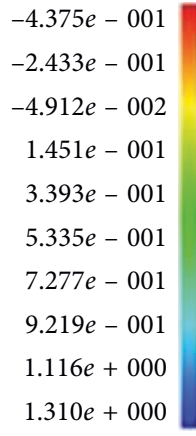

$1.310 e+000$

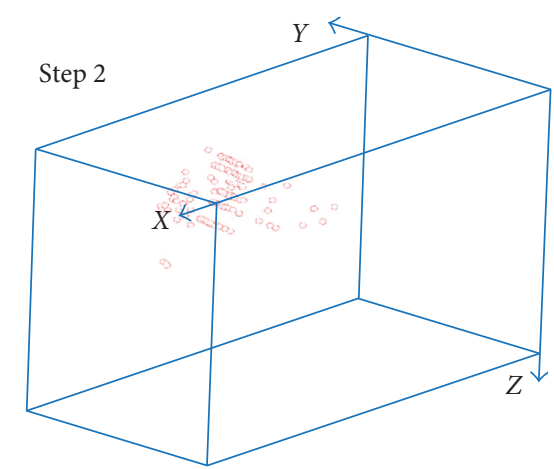

(b)

Figure 15: Continued. 


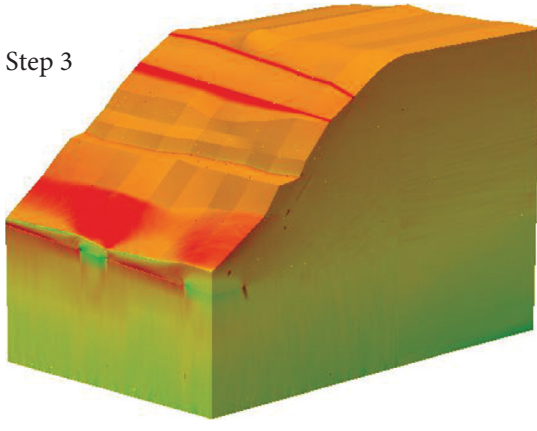

(c)

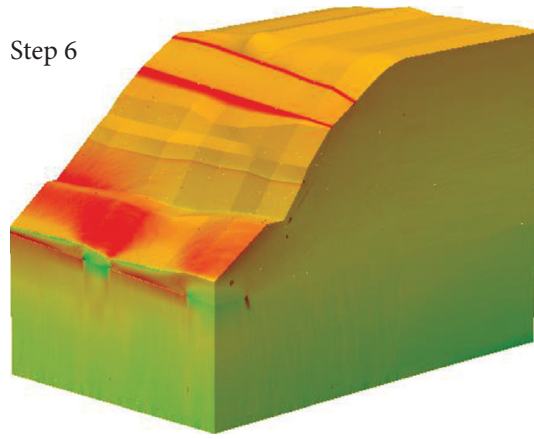

(e)

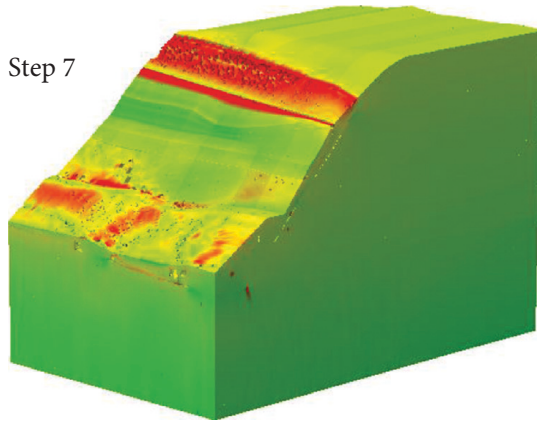

(g)
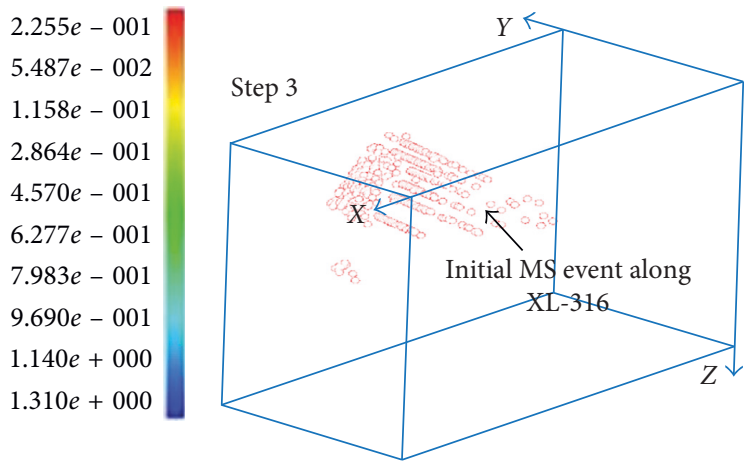

(d)

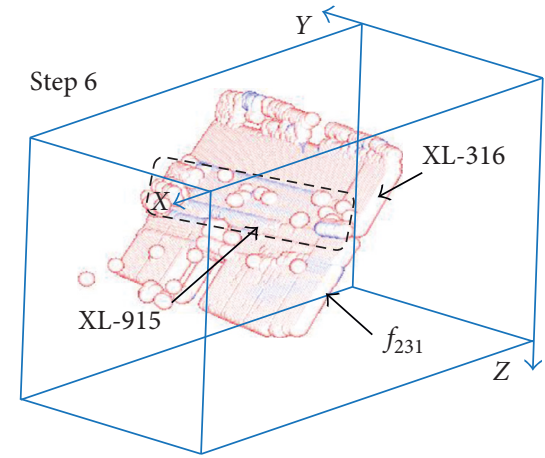

(f)

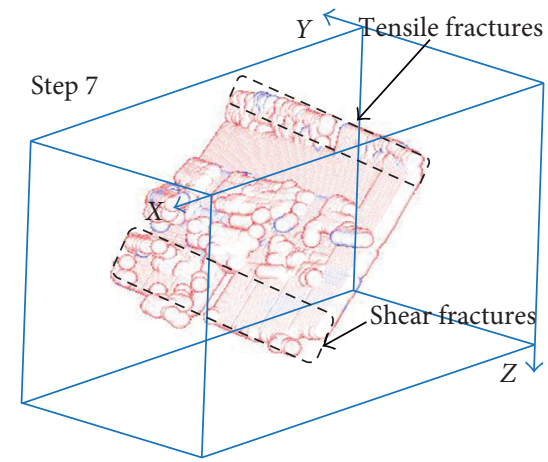

(h)

FIGURE 15: Distribution of the minimum principal stress (a, c, e, g) and AE (b, d, f, h) during the progressive failure processes.

\section{Data Availability}

The data used to support the findings of this study are available from the corresponding author upon request.

\section{Conflicts of Interest}

The authors declare no conflicts of interest.

\section{Authors' Contributions}

K. Ma and N. W. Xu conceived and designed the MS databased numerical models and conducted the MS monitoring; Z. Z. Liang optimized the proposed models; K. Ma and N. W. Xu wrote the paper.

\section{Acknowledgments}

The authors are grateful for the financial support from the National Natural Science Foundation of China (nos. 51679158 and 51504233) and the National Program on Key Basic Research Project (no. 2015CB057903).

\section{References}

[1] J. A. Hudson, A. Bäckström, J. Rutqvist et al., "Characterising and modelling the excavation damaged zone in crystalline rock in the context of radioactive waste disposal," Environmental Geology, vol. 57, no. 6, pp. 1275-1297, 2009.

[2] X. L. Jiang, J. Y. Niu, H. Yang, and F. F. Wang, "Upper bound limit analysis for seismic stability of rock slope with tunnel," 
Advances in Civil Engineering, vol. 2018, Article ID 3862974 , 11 pages, 2018.

[3] C. Q. Qi, J. B. Qi, L. Y. Li, and J. Liu, "Stability analysis method for rock slope with an irregular shear plane based on interface model," Advances in Civil Engineering, vol. 2018, Article ID 8190908, 8 pages, 2018.

[4] C. G. Jin, "Vibrating effect of blasting in open-pit slope," Metallurgy, vol. 227, pp. 18-20, 1995.

[5] X. B. Guo, Z. X. Xiao, and Z. C. Zhang, "Slope effect of blasting vibration," Chinese Journal of Rock Mechanics and Engineering, vol. 20, no. 1, pp. 83-87, 2001.

[6] P. B. Wayne, "The rock mechanics of kimberlite volcanic pipe excavation," Journal of Volcanology and Geothermal Research, vol. 174, no. 1-3, pp. 29-39, 2008.

[7] W. Lu, Y. Hu, J. Yang, M. Chen, and P. Yan, "Spatial distribution of excavation induced damage zone of high rock slope," International Journal of Rock Mechanics and Mining Sciences, vol. 64, pp. 181-191, 2013.

[8] J. Yang, Y. Xia, Z. Chen et al., "Dynamic behavior of Road high Cutting Rock slope under the influence of blasting for excavation," Procedia Earth and Planetary Science, vol. 5, pp. 25-31, 2012.

[9] T. Sato, T. Kikuchi, and K. Sugihara, "In-situ experiments on an excavation disturbed zone induced by mechanical excavation in Neogene sedimentary rock at Tono mine, central Japan," Engineering Geology, vol. 56, no. 1-2, pp. 97-108, 2000.

[10] B. Kentli and T. Topal, "Evaluation of rock excavatability and slope stability along a segment of motorway, Pozanti, Turkey," Environmental Geology, vol. 46, no. 1, pp. 83-95, 2004.

[11] P. W. Xiao, B. Qian, P. Jiang, N. W. Xu, and B. Li, "Deformation forecasting of surrounding rock mass based on correlation between frequency and fracture scale of microseismicity," Advances in Civil Engineering, vol. 2018, Article ID 4037402, 8 pages, 2018.

[12] Z. M. He and B. L. Wang, "Process model test for bedding rock slope with weak interlayer under different rainfall conditions," Advances in Civil Engineering, vol. 2018, Article ID 8201031, 8 pages, 2018.

[13] K. Ma, C. A. Tang, Z. Z. Liang, D. Y. Zhuang, and Q. B. Zhang, "Stability analysis for the right bank slope of Dagangshan hydropower station during excavation and after reinforcement based on microseismic monitoring," Engineering Geology, vol. 218, pp. 22-38, 2017.

[14] Y. I. Kolesnikov, M. M. Nemirovich-Danchenko, S. V. Goldin, and V. S. Seleznev, "Slope stability monitoring from microseismic field using polarization methodology," Natural Hazards and Earth System Sciences, vol. 3, no. 6, pp. 515-521, 2003.

[15] G. Senfaute, V. Merrien-Soukatchoff, J. Morel, and J. C. Gourry, "Microseismic monitoring applied to prediction of chalk cliff collapses and contribution of numerical modelling," in Proceedings of International Conference on Fast Slope Movements-Prediction and Prevention for Risk Mitigation, pp. 463-468, Napoli, Italy, May 2003.

[16] D. Amitrano, J. R. Grasso, and G. Senfaute, "Seismic precursory patterns before a cliff collapse and critical point phenomena," Geophysical Research Letters, vol. 32, no. 8, article L08314, 2005.

[17] E. Eberhardt, T. Spillmann, H. Maurer et al., “The Randa rockslide Laboratory: establishing brittle and ductile instability mechanisms using numerical modelling and microseismicity," in Proceedings of 9th International Symposium of Landslides, pp. 481-487, Rio de Janeiro, Brazil, 2004.
[18] T. Shiotani, "Evaluation of long-term stability for rock slope by means of acoustic emission technique," NDT and E International, vol. 39, no. 3, pp. 217-228, 2006.

[19] T. Spillmann, H. Maurer, A. G. Green et al., "Microseismic investigation of an unstable mountain slope in the Swiss Alps," Journal of Geophysical Research: Solid Earth, vol. 112, no. B7, 2007.

[20] M. Zhang, Z. K. Li, Q. Yang, and X. T. Feng, "A damage model and statistical analysis of acoustic emission for quasi-brittle materials," Chinese Journal of Rock Mechanics and Engineering, vol. 25, no. 12, pp. 2493-2501, 2006.

[21] N. W. Xu, C. A. Tang, H. Li et al., "Excavation-induced microseismicity: microseismic monitoring and numerical simulation," Journal of Zhejiang University Science A, vol. 13, no. 6, pp. 445-460, 2012.

[22] C. Trifu and V. Shumila, "Microseismic monitoring of a controlled collapse in Field II at Ocnele Mari, Romania," Pure and Applied Geophys, vol. 167, no. 1-2, pp. 27-42, 2010.

[23] M. Cai, "Rock mass characterization and rock property variability considerations for tunnel and cavern design," Rock Mechanics and Rock Engineering, vol. 44, no. 4, pp. 379-399, 2011.

[24] N. W. Xu, F. Dai, Z. Z. Liang et al., "The dynamic evaluation of rock slope stability considering the effects of microseismic damage," Rock Mechanics and Rock Engineering, vol. 47, no. 2, pp. 621-642, 2014.

[25] C. A. Tang and P. K. Kaiser, "Numerical simulation of cumulative damage and seismic energy release during brittle rock failure-part I: fundamentals," International Journal Rock Mechanics and Mining Sciences, vol. 35, no. 2, pp. 113-121, 1998.

[26] Z. Z. Liang, H. Xing, S. Y. Wang, D. J. Williams, and C. A. Tang, "A three-dimensional numerical investigation of the fracture of rock specimens containing a pre-existing surface flaw," Computer Geotechnics, vol. 45, pp. 19-33, 2012.

[27] C. A. Tang, L. G. Tham, P. K. K. Lee, T. H. Yang, and L. C. Li, "Coupled analysis of flow, stress and damage (FSD) in rock failure," International Journal Rock Mechanics and Mining Sciences, vol. 39, no. 4, pp. 477-489, 2002.

[28] K. Ma, C. A. Tang, L. C. Li et al., "3D modeling of stratified and irregularly jointed rock slope and its progressive failure," Arabian Journal of Geosciences, vol. 6, no. 6, pp. 2147-2163, 2013.

[29] J. Cao and A. Deng, "Centrifugal loading finite element method for slope stability analysis," Chinese Journal of Geotechnical Engineering, vol. 28, pp. 1336-1339, 2006.

[30] D. P. Adhikary and A. V. Dyskin, "Modelling of progressive and instantaneous failures of foliated rock slopes," Rock Mechanics and Rock Engineering, vol. 40, no. 4, pp. 349-362, 2007.

[31] H. P. Xie, Y. Ju, and L. Y. Li, "Criteria for strength and structural failure of rocks based on energy dissipation and energy release principles," Chinese Journal of Rock Mechanics and Engineering, vol. 24, no. 17, pp. 3003-3010, 2005.

[32] X. L. Qiao, Y. T. Hu, J. H. Peng et al., "TNT equivalence of A Rock emulsion explosive," Explosive Mater, vol. 27, no. 6, pp. 5-8, 1998.

[33] K. Ma, "Study on the potential failure mechanism, monitoring and controlling methods of rock slope under excavation," Ph.D. thesis, Dalian University of Technology, Dalian, China, 2014, in Chinese.

[34] K. Ma, C. A. Tang, L. C. Li et al., "Reinforcement effect analysis of right bank slope anti-shear tunnel of Dagang mountain hydropower station based on micro seismicity monitoring and numerical analysis," Chinese Journal of Rock Mechanics and Engineering, vol. 6, pp. 1239-1247, 2013. 


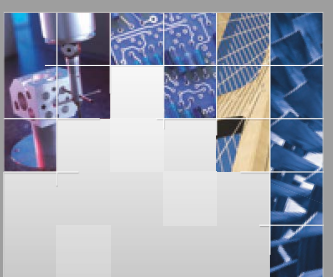

\section{Enfincering}
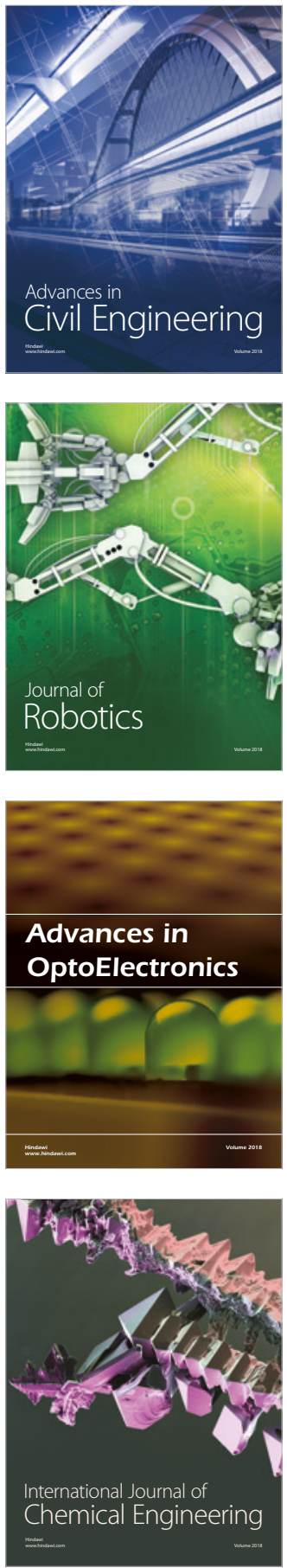

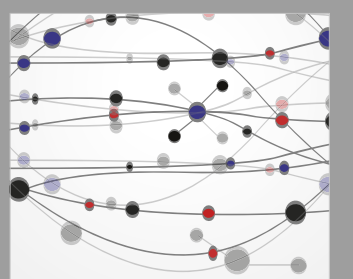

\section{Rotating \\ Machinery}

The Scientific World Journal

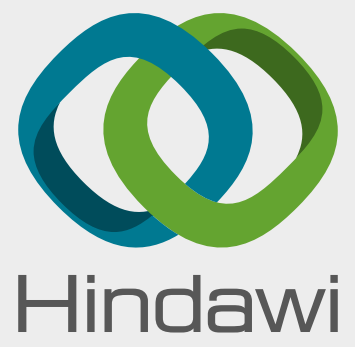

Submit your manuscripts at

www.hindawi.com
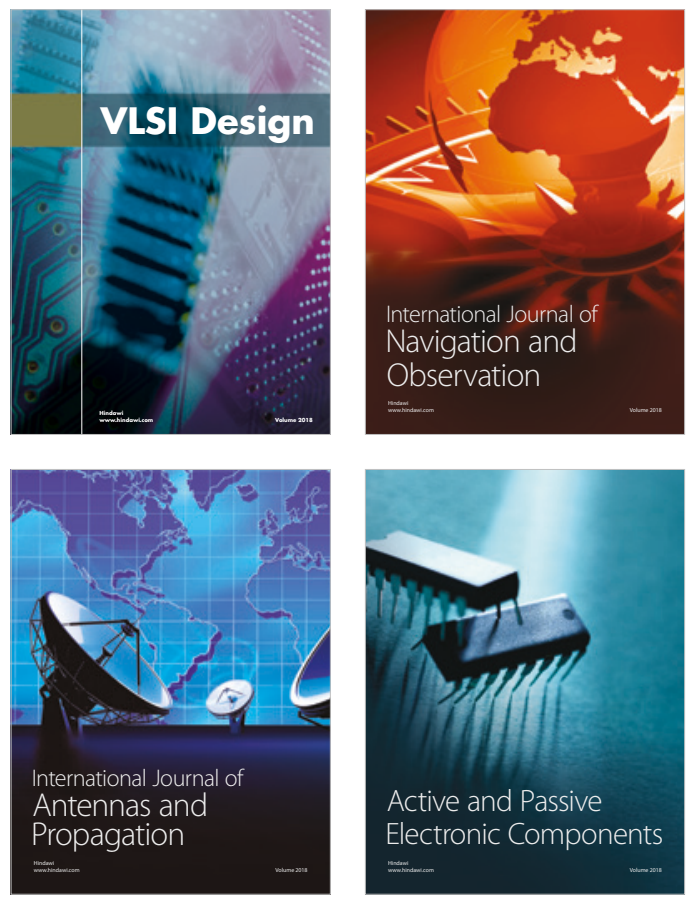
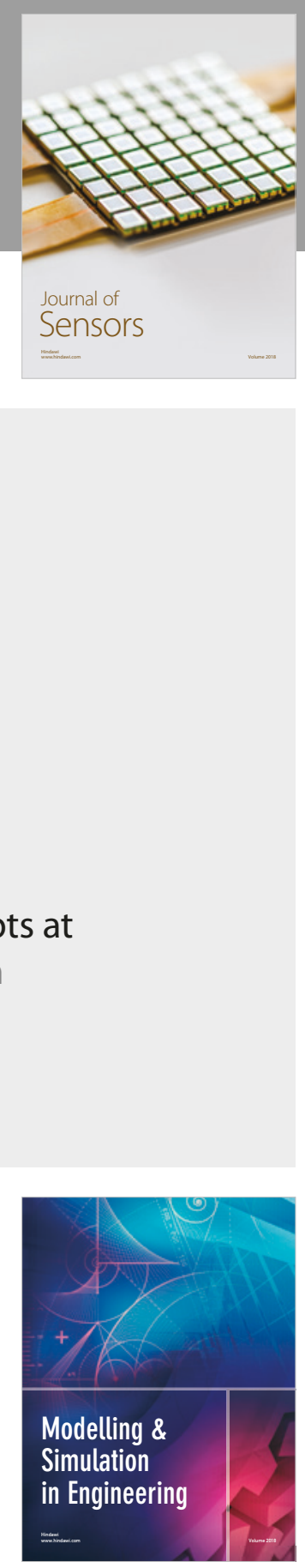

\section{Advances \\ Multimedia}
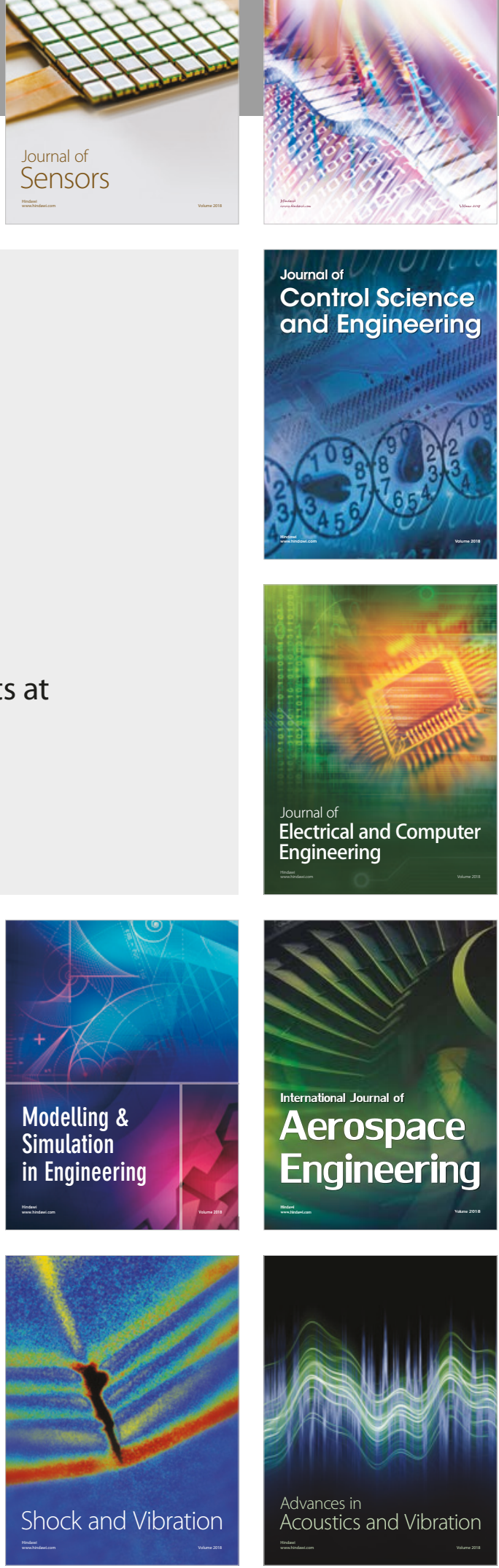